\title{
Second Korean guidelines for the management of ulcerative colitis
}

\author{
Chang Hwan $\mathrm{Choi}^{1 *}$, Won Moon ${ }^{2 *}$, You Sun $\mathrm{Kim}^{3}$, Eun Soo Kim ${ }^{4}$, Bo-In Lee ${ }^{5}$, \\ Yunho Jung ${ }^{6}$, Yong Sik Yoon ${ }^{7}$, Heeyoung Lee ${ }^{8}$, Dong Il Park ${ }^{9}$, Dong Soo Han ${ }^{10}$; \\ IBD Study Group of the Korean Association for the Study of Intestinal Diseases \\ ${ }^{1}$ Department of Internal Medicine, Chung-Ang University College of Medicine, Seoul, ${ }^{2}$ Department of Internal Medicine, Kosin University \\ College of Medicine, Busan, ${ }^{3}$ Department of Internal Medicine, Seoul Paik Hospital, Inje University College of Medicine, Seoul, ${ }^{4}$ Division of \\ Gastroenterology and Hepatology, Department of Internal Medicine, Kyungpook National University School of Medicine, Daegu, ${ }^{5}$ Division \\ of Gastroenterology, Department of Internal Medicine, Seoul St. Mary's Hospital, College of Medicine, The Catholic University of Korea, Seoul, \\ ${ }^{6}$ Division of Gastroenterology, Department of Medicine, Soonchunhyang University College of Medicine, Cheonan, ${ }^{7}$ Division of Colon and Rectal \\ Surgery, Department of Surgery, Asan Medical Center, University of Ulsan College of Medicine, Seoul, ${ }^{8}$ Center for Preventive Medicine and Public \\ Health, Seoul National University Bundang Hospital, Seongnam, ${ }^{9}$ Department of Internal Medicine, Kangbuk Samsung Hospital, Sungkyunkwan \\ University School of Medicine, Seoul, ${ }^{10}$ Department of Internal Medicine, Hanyang University Guri Hospital, Guri, Korea
}

Ulcerative colitis (UC) is a chronic inflammatory bowel disease characterized by a relapsing and remitting course. The direct and indirect costs of the treatment of UC are high, and the quality of life of patients is reduced, especially during exacerbation of the disease. The incidence and prevalence of UC in Korea are still lower than those of Western countries, but have been rapidly increasing during the past decades. Various medical and surgical therapies, including biologics, are currently used for the management of UC. However, many challenging issues exist, which sometimes lead to differences in practice between clinicians. Therefore, the IBD study group of the Korean Association for the Study of Intestinal Diseases established the first Korean guidelines for the management of UC in 2012. This is an update of the first guidelines. It was generally made by the adaptation of several foreign guidelines as was the first edition, and encompasses treatment of active colitis, maintenance of remission, and indication of surgery for UC. The specific recommendations are presented with the quality of evidence and classification of recommendations. (Intest Res 2017;15:7-37)

Key Words: Colitis, ulcerative; Inflammatory bowel disease; Disease management; Guidelines

\section{INTRODUCTION}

Ulcerative colitis (UC) is a chronic IBD localized in the mucosa and submucosa of the colon. The specific cause

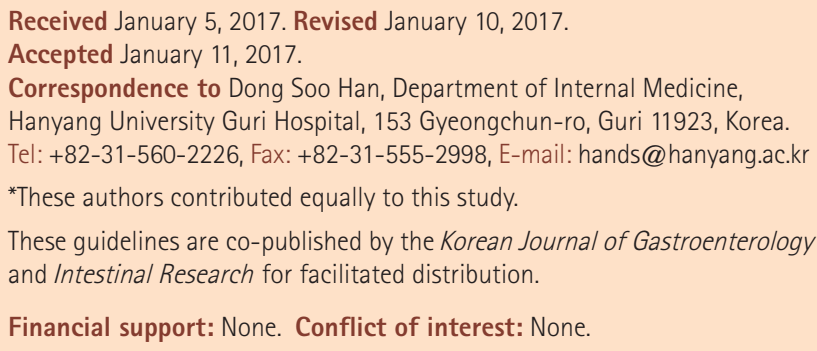

Financial support: None. Conflict of interest: None.

of the disease is unknown. The main symptoms of UC are bloody diarrhea, urgency, and abdominal pain. ${ }^{1,2} \mathrm{UC}$ is considered to be caused by multiple factors such as genetic susceptibility, environmental factors, immune dysregulation, and microbial flora. It is found worldwide but most commonly in North America and Europe. Ethnically, it is most common among Jews and Caucasians, and less common in Asians. ${ }^{2,3}$ However, recently, its incidence is rapidly increasing in Southern Europe, Asian countries such as South Korea, Japan and China, and in developing countries, resulting in the increase in the numbers of patients diagnosed as having UC. ${ }^{3-6}$ Various diagnostic methods and treatments have been suggested based on scientific evidences obtained

\footnotetext{
๑ Copyright 2017. Korean Association for the Study of Intestinal Diseases. All rights reserved.

This is an Open Access article distributed under the terms of the Creative Commons Attribution Non-Commercial License (http://creativecommons.org/licenses/by-nc/4.0)

which permits unrestricted non-commercial use, distribution, and reproduction in any medium, provided the original work is properly cited.
} 
through many studies. However, many problems are still dealt with physicians' subjective judgments and experiences. Therefore, many countries, including the Unites States and Europe, have developed guidelines for UC according to each country's circumstances.

The IBD Study Group of the Korean Association for the Study of Intestinal Diseases (KASID) developed the Korean guidelines for the diagnosis of $\mathrm{UC}^{7}$ by adapting the American and European guidelines ${ }^{8,9}$ in 2009. In 2012, the Korean guidelines for the management of $\mathrm{UC}^{10}$ was developed and published by using the same method of adapting foreign guidelines. ${ }^{1,8,11,12}$ This updated version of the Korean guidelines for the management of UC was developed also by adapting foreign guidelines that were reported within the recent 5 years. ${ }^{13-21}$

These guidelines are not suggesting absolute standards but is aimed at helping physicians make the best decisions for managing patients with UC according to scientific evidences available. Therefore, physicians may make final decisions by considering each patient's specific situations. These guidelines should neither limit the physician's medical practice nor be used to set the standards for Korean medical insurance. Moreover, this does not indicate legal criteria for medical practice conducted on specific patients.

We are hoping that these guidelines will prevent unnecessary or inappropriate or delayed treatments and lessen the confusion among physicians and researchers by making use of the same terms related to UC.

\section{METHODS}

\section{Direction}

The IBD Study Group of the KASID decided to produce an updated version of the Korean guidelines for the management of UC in July 2015. To establish the guidelines, a subcommittee was formed, consisting of eight gastroenterologists who were members of the KASID, one colorectal surgeon who was a member of the Korean Society of Coloproctology, and one professor of preventive medicine who was a methodologist for guidelines development. All members of the subcommittee attended 10 meetings until the completion of the guidelines starting from July 12, 2015.

This updated guidelines included treatment of active colitis, maintenance of remission, and indication of surgery for UC in adults. Managements of specific situations such as extraintestinal manifestations, pouchitis, pediatric or pregnant patients, and colitic cancer surveillance are not included in these guidelines. These guidelines were generally made by the adaptation of foreign guidelines for the management of UC, as was the first Korean guideline. The recommendations for three key questions not precisely included in other guidelines were newly made by using the Grading of Recommendation Assessment, Development and Evaluation (GRADE) format.

\section{Process of Development}

\section{1) Selection of the Key Questions}

The key questions were selected from among those raised in actual clinical practice through subcommittee meetings and discussions. Three of the key questions were decided to be solved by de novo development; and the remaining questions, by adaptations.

\section{2) Searching for Source Guidelines}

Twenty-seven articles with publication dates between January 2011 and June 2015 were selected by searching the MEDLINE/PubMed and National Guidelines Clearinghouse web sites.

\section{3) Assessment of Guideline Qualities and Final Selection}

First, we selected 16 English guidelines based on whether they were evidence based, peer reviewed, and national or international guidelines. Each foreign guideline was evaluated by two subcommittee members on its academic integrity and applicability to actual clinical practice according to the Appraisal of Guidelines Research and Evaluation II. Finally, nine highly qualified guidelines were selected and then analyzed and summarized for their evidences and medical recommendations for our guidelines (Table 1). ${ }^{13-21}$

\section{4) Adaptation}

The evidences and recommendations of the nine selected guidelines were reviewed, analyzed, and summarized for the development of our recommendations and backgrounds. Recent studies that were reported after the search period for referential guidelines were included additionally as evidences for our guidelines. Some of the information was considered not sufficiently evidenced and thus was discussed in the IBD specialist meetings to be included in the guidelines.

The quality of the evidence and classification of the recommendation in these guidelines are presented according to the GRADE format. ${ }^{22-24}$ Following the GRADE format, we assessed the quality of evidence for each recommendation as high, moderate, low, and very low. The strength of each recommendation was evaluated based on four main components, which are desirable and undesirable effects, quality 
of the evidence, values and preference, and lastly, resource allocation, and classified as strong or weak. ${ }^{24,25}$ The definition of quality of evidence and classification of the recommendations are shown in Table $2 .{ }^{22-25}$

\section{5) De novo Development}

De novo development was conducted for three key questions by following the GRADE format as follows: efficacy of cyclosporine and tacrolimus for corticosteroid-refractory

Table 1. Nine Guidelines Selected for Adaptation

\begin{tabular}{|c|c|c|c|c|c|}
\hline No. & Title & Country & Journal & Year & Volume/page \\
\hline 1 & Ulcerative colitis: management in adults, children and young people ${ }^{13}$ & United Kingdom & $\begin{array}{l}\text { National Clinical } \\
\text { Guideline Centre }\end{array}$ & 2013 & - \\
\hline 2 & $\begin{array}{l}\text { Treatment of hospitalized adult patients with severe ulcerative colitis: } \\
\text { Toronto consensus statements }{ }^{14}\end{array}$ & Canada & $\begin{array}{l}\text { American Journal of } \\
\text { Gastroenterology }\end{array}$ & 2012 & 107/179-194 \\
\hline 3 & $\begin{array}{l}\text { Clinical practice guidelines for the medical management of } \\
\text { nonhospitalized ulcerative colitis: the Toronto consensus }{ }^{15}\end{array}$ & Canada & Gastroenterology & 2015 & $148 / 1035-1058$ \\
\hline 4 & $\begin{array}{l}\text { The London position statement of the World Congress of } \\
\text { Gastroenterology on Biological Therapy for IBD with the European } \\
\text { Crohn's and Colitis Organization: when to start, when to stop, which } \\
\text { drug to choose, and how to predict response? }{ }^{16}\end{array}$ & $\begin{array}{l}\text { World Congress of } \\
\text { Gastroenterology }\end{array}$ & $\begin{array}{l}\text { American Journal of } \\
\text { Gastroenterology }\end{array}$ & 2011 & 106/199-212 \\
\hline 5 & $\begin{array}{l}\text { The London position statement of the World Congress of } \\
\text { Gastroenterology on Biological Therapy for IBD with the European } \\
\text { Crohn's and Colitis Organization: safety }\end{array}$ & $\begin{array}{l}\text { World Congress of } \\
\text { Gastroenterology }\end{array}$ & $\begin{array}{l}\text { American Journal of } \\
\text { Gastroenterology }\end{array}$ & 2011 & 106/1594-1602 \\
\hline 6 & $\begin{array}{l}\text { Second European evidence-based consensus on the diagnosis and } \\
\text { management of ulcerative colitis part 2: current management }{ }^{17}\end{array}$ & European Union & $\begin{array}{l}\text { Journal of Crohn's } \\
\text { and Colitis }\end{array}$ & 2012 & 6/991-1030 \\
\hline 7 & $\begin{array}{l}\text { Therapeutic guidelines on ulcerative colitis: a GRADE methodology } \\
\text { based effort of GETECCU }\end{array}$ & Spain & $\begin{array}{l}\text { Gastroenterología y } \\
\text { Hepatología }\end{array}$ & 2013 & $36 / 104-114$ \\
\hline 8 & $\begin{array}{l}\text { Guidelines for the management of inflammatory bowel disease in } \\
\text { adults }^{19}\end{array}$ & United Kingdom & Gut & 2011 & $60 / 571-607$ \\
\hline 9 & $\begin{array}{l}\text { The Italian Society of Gastroenterology (SIGE) and the Italian Group for } \\
\text { the Study of Inflammatory Bowel Disease (IG-IBD) Clinical Practice } \\
\text { Guidelines: the use of tumor necrosis factor- } \alpha \text { antagonist therapy in } \\
\text { inflammatory bowel disease }{ }^{20}\end{array}$ & Italy & $\begin{array}{l}\text { Digestive and Liver } \\
\text { Disease }\end{array}$ & 2011 & $43 / 1-20$ \\
\hline
\end{tabular}

GRADE, Grading of Recommendation Assessment, Development and Evaluation; GETECCU, Grupo Español de Trabajo Enfermedad de Crohn y Colitis Ulcerosa.

Table 2. Definitions or Implications of the Levels of Evidence and Recommendations ${ }^{22-25}$

\begin{tabular}{l}
\hline \multicolumn{1}{c}{ Level } \\
$\begin{array}{l}\text { Quality of evidence } \\
\text { High }\end{array}$ \\
$\begin{array}{l}\text { Woderate } \\
\text { We are modery confident that the true effect lies close to that of the estimate of the effect. } \\
\text { estimate of the effect, but there is a possibility that it is substantially different. }\end{array}$ \\
$\begin{array}{l}\text { Our confidence in the effect estimate is limited: the true effect may be substantially different from the } \\
\text { estimate of the effect. }\end{array}$ \\
$\begin{array}{l}\text { We have very little confidence in the effect estimate: the true effect is most likely to be substantially } \\
\text { different from the estimate of the effect. }\end{array}$ \\
$\begin{array}{l}\text { Classification of recommendations } \\
\text { Strong }\end{array}$ \\
$\begin{array}{l}\text { Meak } \\
\text { Clinicians should recognize that different choices would be appropriate for different patients and } \\
\text { that they must help patients to arrive at a management decision consistent with their values and } \\
\text { preferences. }\end{array}$ \\
\hline
\end{tabular}


severe UC and efficacy of high-dose 5-aminosalicylic acid (5-ASA) for maintenance of remission. The PubMed and EMBASE databases were used for searching evidences about the key questions. Language was limited to Korean and English. The study design included randomized controlled trials (RCTs) and prospective and retrospective cohort studies. Editorials, letters, and proceedings were excluded.

\section{6) Delphi Process for the Agreement to Recommendations}

On September 25, 2016, the draft of the updated Korean guidelines for the management of UC was presented during the consensus meeting attended by 53 national IBD specialists. Each recommendation in the guideline was evaluated into five levels, namely strongly agree, agree, uncertain, disagree, and strongly disagree. Each recommendation in the guidelines were selected when more than $75 \%$ of the participants have answered strongly agree or agree. When the percentage of agreement on the guidelines were below $75 \%$, the guidelines subcommittee went through a discussion and modification, and proceeded with secondary online voting. The secondary online voting for the guidelines proceeded by 49 of the 53 IBD specialists who participated in the primary evaluation. The final result was indicated as a percentage under the classification of recommendation, as "level of agreement."

\section{7) Review, Endorsement, and Distribution of Guidelines}

The revised draft was reviewed and approved by the members of the KASID. The final draft was co-published by the Korean Journal of Gastroenterology and Intestinal Research for facilitated distribution and will be distributed by the Korean Medical Guideline Information Center (http://www. guideline.or.kr). The second updated version is planned to be published, including opinions by users and newly presented information on the management of UC.

\section{THERAPEUTIC APPROACH}

The goal of the management of UC is to improve patients quality of life by relieving mucosal inflammation and maintaining remission as long as possible. Among UC patients, $15 \%$ are known to achieve the remission state even with only placebo treatment. ${ }^{26}$ However, starting and maintaining the appropriate treatments to relieve symptoms such as bloody stool and diarrhea are reasonable. These guidelines are divided into three sections as follows: medical management of active UC, maintenance of remission, and surgical therapy.

The important keys in decision making on the treatment of UC are the extent, severity, and clinical features of the disease. Medications differ in distribution area within the bowel, and topical agents can be locally effective. In addition, the potency and adverse effects of the medication, response to the previous treatment, and extraintestinal manifestations must be considered.

Extent of the disease was classified into proctitis (up to 15 $\mathrm{cm}$ above the anal verge), left-sided colitis (up to the splenic flexure), and extensive colitis (beyond the splenic flexure) according to the diagnostic guideline for UC. ${ }^{7}$ Clinical severity was classified in accordance with the modification of the Truelove and Witts score. ${ }^{27}$ It is divided into remission, mild, moderate, and severe groups (Table 3 ). ${ }^{12}$

5-ASA are described in the main text as treatment agents for UC. There are different types of 5-ASA according to the mediator used to deliver them to the small and large intestines. Sulfasalazine, a combination of sulfapyridine and 5-ASA by azo bond, has been used for a long time. The newly developed 5-ASA are olsalazine (5-ASA dimer), balsalazide (Colazal ${ }^{\circledR}$, 5-ASA combined with 4-amino-benzoyl- $\beta$-alanine by azo bond), Eudragit-S-coated mesalamine (Asacol ${ }^{\circledR}$ ), Eudragit-L-coated mesalamine (Salofalk ${ }^{\circledR}$ ), ethylcelllulosecoated microgranules of mesalamine (Pentasa ${ }^{\circledR}$ ), and MMX mesalamine (Mezavant ${ }^{\circledR}$ ), which is made by using the multimatrix system (MMX) (Table 4).

The new 5-ASA preparations have almost similar effects as sulfasalazine but are safer. The adverse effects of sulfasalazine are usually due to its sulfapyridine component, which

Table 3. Truelove and Witts Score for Clinical Severity of $U^{12,27}$

\begin{tabular}{|c|c|c|c|}
\hline & Mild $^{2}$ & Moderate & Severe $^{b}$ \\
\hline $\begin{array}{l}\text { (1) Frequency of } \\
\text { defection }\end{array}$ & 4 Times or less & $\begin{array}{l}\text { Intermediate } \\
\text { between mild } \\
\text { and severe }\end{array}$ & 6 Times or more \\
\hline (2) Bloody stool & $(-)$ or $(+)$ & & $(+++)$ \\
\hline (3) Fever ${ }^{\mathrm{c}}$ & Absent & & $37.5^{\circ} \mathrm{C}$ or higher \\
\hline (4) Tachycardia ${ }^{d}$ & Absent & & 90/min or more \\
\hline (5) Anemia & Absent & & $\mathrm{Hb} 10 \mathrm{~g} / \mathrm{dL}$ or less \\
\hline (6) ESR & Normal & & $30 \mathrm{~mm} / \mathrm{h}$ or more \\
\hline
\end{tabular}

"Rated as "mild" when all 6 criteria are satisfied.

${ }^{b}$ Rated as "severe" when criteria (1) and (2), and either of systemic symptoms (3) and (4) are satisfied, and at least 4 of the 6 criteria are satisfied.

'Mean evening temperature of $>37.5^{\circ} \mathrm{C}$ or a temperature of $\geq 37.8^{\circ} \mathrm{C}$ at least 2 of 4 days.

${ }^{d}$ Mean pulse rate of $>90 / \mathrm{min}$.

$\mathrm{Hb}$, hemoglobin. 
Table 4. Delivery System for 5-ASA ${ }^{9}$

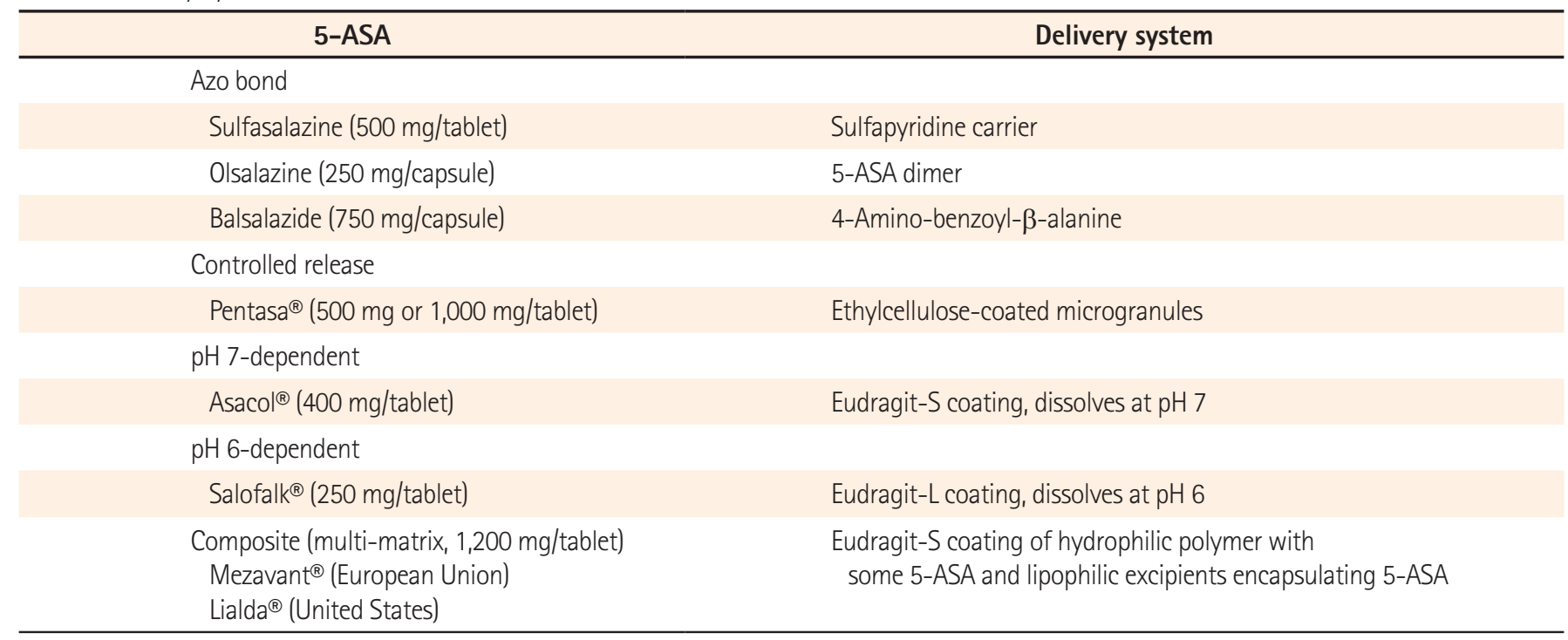

5-ASA, 5-aminosalicylic acid.

causes nausea, vomiting, indigestion, headache, pancreatitis, hepatitis, drug-induced connective tissue disorders, marrow suppression, interstitial nephritis, hemolytic anemia, megaloblastic anemia, and reversible male infertility. ${ }^{1,28-30}$ In $80 \%$ of patients with adverse effects of sulfasalazine use, other 5-ASA provide relief. All 5-ASA except sulfasalazine are recommended to patients with pregnancy plans.

In rare cases, 5-ASA, including sulfasalazine, can lead to nephrotoxicity (yearly prevalence of $0.26 \% /$ person/year). Usually interstitial nephrotoxicity develops in the first year of treatment. It is considered idiosyncratic, as 5-ASA dosage is not associated with nephrotoxicity. Therefore, even though it is not absolutely required, evaluation of serum creatinine level is needed before and after the use of 5-ASA. For the first year, 3 to 6 months of follow-up for evaluation of creatinine level is recommended. After 1 year, yearly evaluation is needed. ${ }^{1,31}$

\section{MEDICAL MANAGEMENT OF ACTIVE UC}

\section{Management of Mild to Moderate UC}

\section{1) Proctitis}

1. The preferred initial treatment of mild to moderate proctitis is administration 5-ASA suppository $1 \mathrm{~g} /$ day or enema 1-2 g/day (quality of evidence, high; classification of recommendation, strong).

- Level of agreement: strongly agree 53.3\%, agree 43.3\%, uncertain 3.3\%, disagree $0 \%$, strongly disagree $0 \%$
2. Topical corticosteroids are recommended when topical 5-ASA are ineffective or have adverse effects (quality of evidence, very low; classification of recommendation, weak).

- Level of agreement: strongly agree 11.4\%, agree 84.1\%, uncertain 4.6\%, disagree 0\%, strongly disagree 0\%

3. Using topical 5-ASA in combination with oral 5-ASA $(\geq 2.0 \mathrm{~g} /$ day) or topical corticosteroid is more effective than using it individually and should be considered for escalation of treatment (quality of evidence, high; classification of recommendation, strong).

- Level of agreement: strongly agree 60.5\%, agree 37.2\%, uncertain 2.3\%, disagree 0\%, strongly disagree 0\%

4. Evaluation of treatment response is recommended after 4-8 weeks of oral/rectal 5-ASA induction therapy to determine the need to modify therapy (quality of evidence, very low; classification of recommendation, strong).

- Level of agreement: strongly agree 15.9\%, agree 72.7\%, uncertain $11.4 \%$, disagree $0 \%$, strongly disagree $0 \%$

5. Oral corticosteroids (prednisolone $30-40 \mathrm{mg} / \mathrm{day}$, or 0.5-1.0 mg/kg) are recommended when 5-ASA and/or topical corticosteroid therapies are ineffective (quality of evidence, low; classification of recommendation, strong).

- Level of agreement: strongly agree 36.4\%, agree 56.8\%, uncertain $4.6 \%$, disagree $2.3 \%$, strongly disagree $0 \%$

If the extent of the disease is limited to the rectum, topical 5-ASA are recommended for initial treatment. Topical 5-ASA have been effective for remission induction in mild to moderate proctitis in several meta-analyses. ${ }^{32-37}$ In a meta-analysis of 11 studies with 778 patients with proctitis or distal 
colitis, placebo treatment showed a remission rate of $7 \%$ to $11 \%$, while topical 5-ASA treatment showed a remission rate of $31 \%$ to $80 \%$ (median, $67 \%$ ). ${ }^{38}$ In a Cochrane meta-analysis that examined 38 clinical trials for proctitis and left-sided colitis, the effect of topical 5-ASA on remission induction was better than that of placebo (OR, 8.30; 95\% CI, 4.28-16.12), endoscopic findings (OR, 5.31; 95\% CI, 3.15-8.92), and histologic findings (OR, 6.28; 95\% CI, 2.74-14.40). ${ }^{37}$ In a recent randomized controlled study for ulcerative proctitis, the remission rate after 4 weeks was $83.8 \%$ in the topical 5-ASA (suppository) group, which was higher than the $36.1 \%$ in the placebo group. $^{39}$

The percentage of residual drug 4 hours after rectal administration was $40 \%$ for the foam type but only $10 \%$ for the liquid type. ${ }^{40}$ Therefore, suppositories may be more effective in delivering the drug directly to the inflammatory lesion of proctitis. A topical 5-ASA dose of 0.25 to $1 \mathrm{~g}$ /day is effective, and a dose higher than $1 \mathrm{~g}$ /day has no dose response. ${ }^{41}$ No difference in effect was found between using 5-ASA suppository once a day and dividing the same dosage to twice or three times a day. ${ }^{42,43}$

In a meta-analysis, topical corticosteroids presented better outcomes than placebo in terms of remission induction. ${ }^{44}$ However, topical 5-ASA showed better effects on symptom relief (OR, 2.42; 95\% CI, 1.72-3.41), endoscopic findings (OR, 1.89; 95\% CI, 1.29-2.76), and histological finings (OR, 2.03; 95\% CI, 1.28-3.20) than topical corticosteroids. ${ }^{44}$ A meta-analysis of six clinical trials showed that topical 5-ASA had better outcomes than topical corticosteroids in terms of symptom remission (OR, 1.65; 95\% CI, 1.11-2.45). ${ }^{37} 5$-ASA also showed better effects on remission induction compared with topical budesonide. ${ }^{44-46}$ Therefore, topical corticosteroids should be used in patients who fail to respond to topical 5-ASA or who experience adverse effects of topical 5-ASA use. ${ }^{47}$

Previous studies reported that topical 5-ASA show better effects than the oral 5-ASA in proctitis. ${ }^{48}$ However, a metaanalysis of four clinical trials showed that topical 5-ASA did not have better outcomes than oral 5-ASA in terms of symptom relief (OR, 2.25; 95\% CI, $0.53-9.54 ; P=0.27)$ or remission induction (RR, 0.82; 95\% CI, 0.52-1.28). ${ }^{34,37}$ In using oral 5-ASA alone, $3.6 \mathrm{~g} /$ day showed better outcomes than lowdose 5-ASA or placebo. Therefore, high-dose administration may be better when oral 5-ASA monotherapy is used in proctitis. ${ }^{49}$ No study has evaluated the effect of combination therapy with oral and topical 5-ASA on proctitis. However, combination therapy has been demonstrated to be better than monotherapy in the treatment of left-sided colitis located within $50 \mathrm{~cm}$ above the anal verge. ${ }^{50}$ In addition, com- bination therapy with a topical 5-ASA and a topical corticosteroid will be more effective than using them individually. Combined treatment with beclomethasone dipropionate (BDP; $3 \mathrm{mg}$ ) and 5-ASA enema (2 g) has shown better clinical, endoscopic, and histological outcomes than using them separately as monotherapy. ${ }^{51}$

In a randomized controlled study on 5-ASA treatments, symptomatic remission was induced in $10 \%$ to $30 \%$ of patients after 2 weeks of treatment, $30 \%$ to $45 \%$ of patients after 4 weeks, and $45 \%$ to $50 \%$ of patients after 8 weeks. ${ }^{52,53}$ The median period to symptomatic remission was 10 to 37 days. ${ }^{52,53}$ Generally, the response to 5-ASA appeared within 2 to 4 weeks of treatment, and additional effect may continue until 16 weeks. ${ }^{45,46,50,33-56}$ If symptoms are not improved within 4 to 8 weeks of 5-ASA treatment, other therapies can be considered. If adequate administration of topical and/ or oral 5-ASA and topical corticosteroids does not alleviate symptoms or if systemic symptoms are observed during the treatment, oral corticosteroids can be used. If oral corticosteroid treatment does not improve the symptoms, biological therapy can be considered. ${ }^{17}$

\section{2) Left-Sided and Extensive Colitis}

6. Oral $5-\mathrm{ASA}$ at a dosage of $\geq 2.4 \mathrm{~g} /$ day is recommended for mild to moderate left colitis and extensive colitis (quality of evidence, moderate; classification of recommendation, strong).

- Level of agreement: strongly agree $74.5 \%$, agree $23.4 \%$, uncertain 2.1\%, disagree 0\%, strongly disagree 0\%

7. Combination therapy with oral 5-ASA and topical 5-ASA $(0.25-1.0 \mathrm{~g} /$ day) is more effective than monotherapy with oral 5-ASA (quality of evidence, low; classification of recommendation, strong).

- Level of agreement: strongly agree 48.9\%, agree 44.7\%, uncertain 4.3\%, disagree 2.1\%, strongly disagree 0\%

8. Remission induction effect is similar between taking oral 5-ASA once a day and taking the same dosage divided times a day. Therefore, decision should be made based on patient's preference and compliance (quality of evidence, moderate; classification of recommendation, strong).

- Level of agreement: strongly agree $44.9 \%$, agree $55.1 \%$, uncertain $0 \%$, disagree 4.6\%, strongly disagree $0 \%$

9. Oral corticosteroid (prednisolone 30-40 mg/day, or $0.5-1.0 \mathrm{mg} / \mathrm{kg}$ ) is recommended when adequate use of 5-ASA is ineffective or accompanied by systemic symptoms (quality of evidence, low; classification of recommendation, strong).

- Level of agreement: strongly agree 48.9\%, agree 51.1\%, uncertain $0 \%$, disagree $0 \%$, strongly disagree $0 \%$ 
Oral 5-ASA are recommended for remission induction in patients with mild to moderate left-sided and extensive colitis. ${ }^{32,57}$ A meta-analysis about the effect of oral 5-ASA in mild to moderate UC showed that the remission failure rate in the oral 5-ASA group (0.86; 95\% CI, 0.81-0.91) was lower than that in the placebo group $(0.79 ; 95 \% \mathrm{CI}, 0.73-0.85)$, indicating the therapeutic effects of oral 5-ASA treatment in mild to moderate UC. ${ }^{32,58,59}$ Another meta-analysis reported that oral 5-ASA treatment was twice more effective than placebo ${ }^{60}$ and that the remission induction rate of 5-ASA was about $20 \%$ to $40 \%{ }^{61}$ In meta-analyses, oral 5-ASA treatment was more effective when it was administrated at $\geq 2.0 \mathrm{~g} /$ day. ${ }^{58,59} \mathrm{In}$ addition, in the ASCEND II study (Assessing the Safety and Clinical Efficacy of a New Dose of 5-ASA), the median time to rectal bleeding cessation was 9 days with $4.8 \mathrm{~g} /$ day of oral 5-ASA, which was significantly lower than the median time of 16 days of oral 5-ASA at $2.4 \mathrm{~g} /$ day $(P<0.05){ }^{62}$ Therefore, administration of $2.4 \mathrm{~g} /$ day of oral 5-ASA may be adequate for mild UC. However, considering that high-dose oral 5-ASA does not result in any adverse effect, a higher dose of oral 5-ASA is recommended for patients with moderate UC. In a randomized case-control study, $10 \%$ to $30 \%$ of patients showed symptom remission in the second week of 5-ASA treatment; $30 \%$ to $45 \%$, in the fourth week; and $45 \%$ to $50 \%$, in the eighth week. Most of the patients showed response to the 5-ASA treatment within 2 to 4 weeks of treatment and additional effect continued until 16 weeks. ${ }^{45,46,50,53-56}$

For mild to moderate left-sided and extensive colitis, combination therapy with oral and topical 5-ASA treatment is recommended. Topical therapy can elevate the 5-ASA level in the rectal mucosa more than oral therapy, which can result in clinical improvement. ${ }^{63}$ A meta-analysis of four randomized placebo-controlled studies revealed that combined treatment with oral and topical 5-ASA is more effective than oral 5-ASA monotherapy (remission failure rate, 0.65; 95\% CI, 0.47-0.91). ${ }^{34}$ In addition, the remission induction rate with combination therapy with oral 5-ASA (Pentasa ${ }^{\circledR}$ ) at $4 \mathrm{~g} /$ day and rectal enema at $1 \mathrm{~g}$ /day in 8 weeks is $64 \%$, which is significantly higher than the remission induction rate of $43 \%$ with oral 5-ASA monotherapy. ${ }^{64}$

In the past, sulfasalazine was the primary choice for oral 5-ASA medication. Recently, mesalamine has been most commonly used. Other 5-ASA such as olsalazine and balsalazide, are also used and have better therapeutic effects than placebo for active UC. ${ }^{60}$ The choice of oral 5-ASA agents is based on consideration of tolerance, prescription, and price. Meta-analyses revealed no difference in effect or safety between the types of 5-ASA. ${ }^{58,65}$ Therefore, changing oral 5-ASA to different types of 5-ASA because of lack of response is not recommended. Choosing a different method of treatment will be a better option.

As the effect of oral 5-ASA can differ according to its dosage rather than delivery method, patients' compliance is an important factor. Recent studies showed that taking oral 5-ASA once a day presented similar or even better results than dividing the same dosage twice or three times a day ${ }^{66,67} \mathrm{~A}$ meta-analysis of 11 studies showed that remission rate (RR, $0.95 ; 95 \% \mathrm{CI}, 0.82-1.10)$ and response rate (RR, $0.87 ; 95 \% \mathrm{CI}$, 0.68-1.10) had no significant difference between the patients with mild to moderate UC who took oral 5-ASA once a day or three times a day. ${ }^{66}$ In addition, most patients preferred once a day administration to dividing the dose ${ }^{67,68}$ Therefore, in mild to moderate UC, administration of oral 5-ASA once a day is recommended for remission induction in consideration of patients' compliance. However, dividing the dose could be chosen according to the patient's preference.

MMX mesalamine is a medication that was newly developed by using the MMX technique and widely distribute the high concentration of 5-ASA ( $1.2 \mathrm{~g} /$ tablet) throughout the whole colon mucosa when taken once a day. In patients with mild to moderate UC, remission rate after 8 weeks in the MMX mesalamine $4.8 \mathrm{~g}$ once daily group and $2.4 \mathrm{~g}$ twice daily group showed no significant difference ( $29 \%$ vs. $34 \%$ ) but was significantly different from that with placebo (13\%). ${ }^{69}$ In a comparison study between MMX mesalamine and Asacol $^{\circledR}$, the clinical remission rate in mild to moderate UC was $40.5 \%$ in patients who received MMX mesalamine $2.4 \mathrm{~g} /$ day and $41.2 \%$ in patients who received MMX mesalamine $4.8 \mathrm{~g} /$ day. These results showed significant differences in remission rate when compared with that in placebo $(22.1 \%$; $P=0.010$ and $P=0.007$, respectively) but no significant difference with Asacol $^{\circledR}(2.4 \mathrm{~g} /$ day, $32.6 \%) .^{70}$

For patients with mild to moderate UC, oral corticosteroid treatment could be decided according to the effect of 5-ASA and patients' tolerance and preference for treatments. The effect of corticosteroid therapy on UC has been reported since the 1960s. Physicians should discuss with their patients the effect and possible adverse effects of using corticosteroids. If adequate 5-ASA therapy ( $\geq 2.4 \mathrm{~g} /$ day) combined with topical treatment does not improve the patient's symptom or if the symptom remains even after 4 weeks of proper treatment, additional oral corticosteroid therapy is needed. ${ }^{17}$ Oral corticosteroid can also be used for patients with worsening symptoms during azathioprine (AZA) maintenance therapy. Europe and the United States have differing opinions about when to start the corticosteroid treatment. In Europe, corti- 
costeroids are used early because of late response to 5-ASA, whereas in the United States, their use is delayed because of the potential adverse effects.

No definite guidelines have been established yet for optimal corticosteroid use for UC. However, according to a metaanalysis, corticosteroids administered at a dosage of $\geq 60 \mathrm{mg}$ / day have no additional effect. Therefore, oral corticosteroids (prednisolone) 30 to $40 \mathrm{mg} /$ day are recommended for remission induction. ${ }^{71}$ Usually, a dosage of 30 to $40 \mathrm{mg} /$ day is recommended until clinical improvement is observed and is tapered to 5 to $10 \mathrm{mg}$ per week up to $20 \mathrm{mg}$. Thereafter, lowering the dosage to $2.5 \mathrm{mg}$ per week is recommended. ${ }^{72,73}$ The Japanese UC management guidelines recommend prednisolone 30 to $40 \mathrm{mg} /$ day. ${ }^{12}$ There are at high risk of early recurrence in active UC when using corticosteroids in less than 3 weeks. Prednisolone $<15 \mathrm{mg} /$ day is ineffective for primary treatment. ${ }^{74}$ Corticosteroid is highly effective for remission induction; however, $50 \%$ of patients can experience adverse effects such as acne, emotional change, or edema. ${ }^{17}$

BDP has few systemic adverse effects due to its low bioavailability. It is also effective for remission induction of mild to moderate UC. ${ }^{75}$ Among patients with mild to moderate UC that was unresponsive to oral 5-ASA, when oral BDP 10 $\mathrm{mg} /$ day was used for 8 weeks and followed $5 \mathrm{mg}$ /day for 4 weeks, $75 \%$ showed clinical remission at 8 weeks and $58 \%$ remained in remission state for 1 year without using corticosteroid therapy. ${ }^{76}$ In addition, in a meta-analysis of seven randomized placebo-controlled studies that compared remission induction and clinical improvement between 5-ASA and BDP for mild to moderate UC, no significant difference (OR, $0.76 ; 95 \% \mathrm{CI}, 0.56-1.03 ; P=0.08$ ) was found, as well as adverse effects. ${ }^{77}$ Budesonide MMX is a newly developed topical corticosteroid that was reported in the Colonic Release Budesonide I and II studies to show effectiveness in mild to moderate UC patients who were intolerant or nonresponsive to 5-ASA. ${ }^{78,79}$ Therefore, using topical corticosteroids should be considered before using systemic corticosteroids.

\section{3) Corticosteroid-Refractory Mild to Moderate UC}

10. Anti-tumor necrosis factor (TNF) therapy is recommended when adequate dosage and duration of treatment with corticosteroid or combination of corticosteroid and thiopurine do not improve symptoms, or if the treatment is not tolerable to the patient (quality of evidence, high; classification of recommendation, strong).

- Level of agreement: strongly agree 55.6\%, agree 44.4\%, uncertain $0 \%$, disagree $0 \%$, strongly disagree $0 \%$
The possibility of cytomegalovirus (CMV) reactivation or Clostridium difficile infection must be considered in active UC patients who are unresponsive to corticosteroid treatment.

Studies on thiopurine therapy (6-mercaptopurine [6-MP] or AZA) for remission induction in active UC are rare ${ }^{80,81}$ In one randomized case-control study, the effect of combination therapy with corticosteroid and AZA ( $2 \mathrm{mg} / \mathrm{kg} /$ day $)$ on clinical and endoscopic remission induction was better than that of monotherapy with oral 5-ASA in patients with corticosteroid-dependent UC (intent-to-treat analysis, 53\% vs. 21\%; OR, 4.78; 95\% CI, 1.57-14.50). ${ }^{80}$ However, for patients with active UC, thiopurine monotherapy is not recommended because it requires at least 2 to 3 month to take effect. ${ }^{22,83}$ Thiopurine therapy is mostly used to lower the corticosteroid dosage in corticosteroid-dependent patients rather than to induce remission. ${ }^{80,84-89}$

Anti-TNF therapy is recommended to patients with moderate UC when adequate dosage and duration of treatment with corticosteroid or combination of corticosteroid and thiopurine do not improve symptoms or are not tolerated by the patient. Still, studies about the effect of anti-TNF therapy on mild UC are rare. In South Korea, infliximab, adalimumab, and golimumab are used as anti-TNF therapy, all of which showed therapeutic effects in terms of remission induction and maintenance in patients with moderate to severe active UC.

The effect of infliximab was clearly proved through two large-scale RCTs, namely Active UC Trials 1 (ACT-1) and 2 (ACT-2). ${ }^{90}$ The ACT study analyzed the clinical response and remission rates of 728 patients with moderate to severe UC by dividing them into three groups as follows: the infliximab $5 \mathrm{mg} / \mathrm{kg}$, infliximab $10 \mathrm{mg} / \mathrm{kg}$, and placebo groups. The ACT-1 study was conducted with patients who showed no response to corticosteroid or thiopurine treatment. The results of the ACT-1 study showed significantly higher clinical response rate to infliximab treatment than to placebo in the 8th, 30th, and 54th weeks $(5 \mathrm{mg} / \mathrm{kg}, 10 \mathrm{mg} / \mathrm{kg}$, and placebo, respectively; $45 \%, 44 \%$, and $20 \%$, respectively; $P<0.001$ ), and a post hoc analysis also showed lower colectomy rate in the infliximab-treated group than in the placebo group. ${ }^{91}$

Adalimumab is also effective in patients with moderate to severe UC regarding remission induction. Among patients with moderate to severe UC treated with corticosteroid or immunomodulators, the adalimumab 160/80 mg (18.5\%) group showed a higher remission rate than the placebo group (9.2\%) at 8 weeks of treatment in UC long-term remission and maintenance with adalimumab 1 (ULTRA 1) study. ${ }^{92}$ In addition, in the ULTRA 2 study, remission rate at 
8 weeks was higher in the $160 / 80 \mathrm{mg}$ adalimumab group (16.5\%) than in the placebo group $(9.3 \%)(P=0.019)$ and that at the 52 weeks of treatment was also significantly higher in the adalimumab group (17.3\%) than in the placebo group $(8.5 \%)(P=0.004){ }^{93}$ In a subanalysis of patients with moderate to severe UC who previously used infliximab and were currently using corticosteroids or immunomodulators, the remission rate at the 52 weeks without corticosteroid use was significantly higher in the adalimumab group (10.2\%) than in the placebo group (3.0\%). ${ }^{93}$ Therefore, it is proved in the ULTRA 1 and ULTRA 2 studies that adalimumab is more effective for remission induction than placebo in patients with moderate to severe UC who showed lack of response to corticosteroids or immunomodulators (remission failure OR, 0.60; 95\% CI, 0.42-0.86). ${ }^{92,93}$

The effect of golimumab was confirmed in the Program of UC Research Studies Utilizing an Investigational TreatmentSubcutaneous (PURSUIT-SC), which presented a significant difference in remission rate at the 6 weeks of treatment, $51.0 \%$ in the golimumab $200 \mathrm{mg} / 100 \mathrm{mg}$ group and $30.3 \%$ in the placebo group $(P<0.001) .{ }^{94}$

In recent UC SUCCESS study, patients with moderate to severe UC who never used anti-TNF therapy showed a significant difference in remission rate without corticosteroids at 16 weeks. The remission rate of the group who received combination therapy with infliximab and AZA was $39.7 \%$, which was higher than those of the groups who received infliximab monotherapy (22.1\%) and AZA monotherapy $(23.7 \%))^{95}$ This study proved that thiopurine therapy increases the remission rate in UC as well as CD by suppression of immunogenicity, which lowers the production of the antiinfliximab-antibody.

\section{Management of Moderate to Severe UC}

\section{1) Conventional and Corticosteroid Therapies}

11. Oral corticosteroid administration is recommended as initial remission induction treatment of moderate to severe UC (quality of evidence, moderate; classification of recommendation, strong).

- Level of agreement: strongly agree 52.2\%, agree $45.7 \%$, uncertain $2.2 \%$, disagree $0 \%$, strongly disagree $0 \%$

12. Patients with severe UC who have systemic toxic symptoms need to be admitted and treated with intravenous corticosteroids (methylprednisolone $40-60 \mathrm{mg} /$ day or hydrocortisone $300-400 \mathrm{mg} /$ day) (quality of evidence, high; classification of recommendation, strong).

- Level of agreement: strongly agree 85.1\%, agree 14.9\%, uncertain $0 \%$, disagree $0 \%$, strongly disagree $0 \%$
13. To confirm the response of patients with severe UC to intravenous corticosteroid treatment, frequency of bowel movement, CRP level, and simple abdominal radiography must be assessed within 3-7 days after treatment. If no improvement is observed after 7-14 days, further treatment methods, including intravenous cyclosporine therapy, anti-TNF therapy, and surgery must be discussed (quality of evidence, moderate; classification of recommendation, strong).

- Level of agreement: strongly agree 53.2\%, agree 44.7\%, uncertain $0 \%$, disagree $2.1 \%$, strongly disagree $0 \%$

According to a meta-analysis of five randomized placebocontrolled studies, remission induction with corticosteroid was excellent compared with placebo treatment, and the relative risk of remission failure was 0.65 (95\% CI, 0.45-0.93). ${ }^{96}$ Although the adequate corticosteroid dosage is not yet known, 40 to $60 \mathrm{mg} /$ day oral prednisolone is mostly recommended because no additional response was found in dosages of $>60 \mathrm{mg} /$ day in the meta-analysis. ${ }^{71}$ However, half of the patients experience short-term adverse effects such as acne, edema, sleep disorder, mood disorder, glucose intolerance, and indigestion. ${ }^{97,98}$

Acute severe UC with systemic symptoms is considered a medical emergency, and the patient must be admitted and treated with intravenous corticosteroids. Administration of intravenous corticosteroids has been demonstrated to significantly lower the mortality rate in such patients. ${ }^{71,99}$ Various intravenous corticosteroid therapies are available. However, the types of medication or method of injection (bolus vs. continuous) does not lead to a difference in effect. ${ }^{100}$ Currently, intravenous methylprednisolone 40 to $60 \mathrm{mg}$ /day or its equivalent is recommended. ${ }^{71}$

Few studies have been conducted on the effect of topical and intravenous corticosteroid combination therapy. However, if the patient is compliant, suppository therapy or corticosteroid or 5-ASA enema therapy can be used. ${ }^{101}$ Moreover, when the patient is capable of taking oral medication, 5-ASA can be used together with intravenous corticosteroid therapy. Adequate fluid supply is important to correct dehydration and electrolyte imbalance. Potassium supplement ( $\geq 60 \mathrm{mmol} /$ day) is particularly necessary to prevent toxic megacolon.

Stool cultures for concurrent bacterial or amebic infection and $C$. difficile toxin assay should be performed. If pathogens are detected, appropriate antibiotics must be administered. The prevalence of $C$. difficile infection in patients with UC is three times higher than that in patients with non-IBD. ${ }^{102} C$. difficile infection shows four times higher mortality rate in patients with IBD than in other patients. ${ }^{103}$ Therefore, early 
detection of $C$. difficile toxin and adequate treatment are crucial in patients with severe UC.

Severe UC should be assessed with an early flexible sigmoidoscopy with minimal air insufflation. Colonoscopy is contraindicated in patients with acute severe UC because of its possible adverse effects such as colon perforation or toxic megacolon.

Medications such as NSAIDs, antidiarrheal drugs, antispasmodics, and narcotic analgesics need to be used cautiously for severe UC because they can cause toxic megacolon. ${ }^{104}$ Hemoglobin level must be maintained at $\geq 10 \mathrm{~g} / \mathrm{dL}$, and blood transfusion is performed if needed.

It is critical to make an early decision for the subsequent therapy based on the response to intravenous corticosteroids. Delays in surgery or in providing second-line medical treatment for the patient who is unresponsive to intravenous corticosteroids may lead to worsening of clinical outcomes. ${ }^{105}$

Two main methods of assessing the treatment response of UC are stool frequency and serum CRP level. ${ }^{106-108}$ According to the Oxford criteria, nonresponse is defined as a CRP level of $\geq 45 \mathrm{mg} / \mathrm{L}$ and a stool frequency of three to eight times a day, or a stool frequency of $>8$ times a day after 3 days of treatment. These criteria correspond well to the need of colectomy on the same admission. ${ }^{106,109}$ Studies have reported that severity assessed based on colonoscopic findings can predict corticosteroid treatment failure and surgery rates. However, because of the potential colon perforation risk, full colonoscopy is not recommended. ${ }^{110,111}$ Other indexes evaluated on day 1 or 3 of hospitalization that have been reported to predict corticosteroid failure include ESR, albumin level, stool calprotectin level, and abdominal imaging findings. However, these indexes have limitations, and further studies are needed for validation. ${ }^{112,113}$ As these indexes are not definite, closer observation of the patient's condition and cooperation with the surgeon are more important in making decisions about the treatment method and appropriate timing of the surgical intervention.

14. A normal diet or enteral nutrition is recommended for patients with moderate to severe UC (quality of evidence, low; classification of recommendation, strong).

- Level of agreement: strongly agree 28.6\%, agree 66.7\%, uncertain 4.8\%, disagree 0\%, strongly disagree 0\%

15. Total parenteral nutrition (TPN) is not effective as a primary treatment and only considered when enteral nutrition is not possible in malnourished patients (quality of evidence, low; classification of recommendation, strong).

- Level of agreement: strongly agree $17.8 \%$, agree $71.1 \%$, uncertain $11.1 \%$, disagree $0 \%$, strongly disagree $0 \%$
16. Antibiotics are not recommended when no evidence indicates infection (quality of evidence, moderate; classification of recommendation, strong)

- Level of agreement: strongly agree $32.6 \%$, agree $54.4 \%$, uncertain $8.7 \%$, disagree $2.2 \%$, strongly disagree $0 \%$

No evidence supports that nil per os (NPO, nothing by mouth) diet improves the course of severe UC. A small-scale prospective study showed no clinical difference between a TPN group with NPO and an oral diet group. ${ }^{114-116}$ Total enteric nutrition with polymeric formula, which can be primary therapy for active $\mathrm{CD}$, does not have therapeutic benefits for patients with UC. TPN with NPO is needed for patients who cannot receive orally or who have been scheduled to undergo colectomy.

Use of antibiotics in addition to corticosteroids has no additional benefit over corticosteroid therapy alone. In a RCT with a small number of patients with severe UC who needed admission, no significant difference was found between the metronidazole or ciprofloxacin treatment group and the placebo treatment group. ${ }^{117-119}$ However, if a patient shows signs of sepsis or $C$. difficile infection, administration of the appropriate antibiotic should be indicated.

\section{2) Steroid-Refractory Moderate to Severe UC}

17. Anti-TNF therapy is recommended for patients with moderate to severe UC who do not respond to corticosteroid therapy (quality of evidence, high; classification of recommendation, strong).

- Level of agreement: strongly agree 60.9\%, agree 32.6\%, uncertain $6.5 \%$, disagree $0 \%$, strongly disagree $0 \%$

Anti-TNF agents such as infliximab, adalimumab, and golimumab are effective for remission induction and maintenance of moderate to severe UC. Meta-analyses of RCTs reported the effect of infliximab in patients who were using corticosteroids or unresponsive to corticosteroids. ${ }^{120-122} \mathrm{~A}$ meta-analysis of five studies showed that infliximab was more effective than placebo based on endoscopic findings (endoscopic remission failure RR, 0.72; 95\% CI, 0.57-0.91; $P=0.006) .{ }^{120}$ In the ACT- $1(\mathrm{n}=364)$ and ACT-2 $(\mathrm{n}=364)$ studies, infliximab showed a higher clinical remission rate (RR, 3.22; 95\% CI, 2.18-4.76) and higher endoscopic remission rate (RR, 1.88; $95 \% \mathrm{CI}, 1.54-2.28$ ) than placebo. ${ }^{121}$

A RCT compared infliximab $(n=24)$ and placebo $(n=21)$ in patients with intravenous corticosteroid-refractory moderate to severe UC. When the patients were assessed as having fulminant colitis after 3 days of treatment with intravenous 
corticosteroid, infliximab was administered on the 4th day. When the patients had moderate to severe activities, infliximab was administered on the 6th to the 8th day of treatment. After 3 months, the placebo group had a higher rate of colectomy than the infliximab group (14 vs. 7: OR, 4.9; 95\% CI, $1.4-17.0 ; P=0.017) .{ }^{123}$

A meta-analysis of the ULTRA $1(\mathrm{n}=390)^{92}$ and ULTRA $2(n=494)^{93}$ studies that investigated the effect of adalimumab on corticosteroid- or immunomodulator-refractory moderate to severe UC, adalimumab has shown to be more effective for remission induction than placebo (remission failure OR, 0.60; 95\% CI, 0.42-0.86; $P=0.006$ ). In PURSUITSC $(\mathrm{n}=774)$ of moderate to severe UC, golimumab treatment was associated with an $18 \%$ remission rate; and placebo, with 6\% $(P<0.0001){ }^{94}$

Evidence is insufficient to recommend a specific anti-TNF agent. In studies that compared between anti-TNF agents and placebo, the adverse effects of the treatments were not significantly different between the two groups, such as infusion reaction, headache, rash, or arthralgia. ${ }^{120}$ However, continuous use of anti-TNF agents showed more adverse effects associated with sensitization. In addition, anti-TNF agents need to be used cautiously because it increases the risk of opportunistic infection. . $^{12,125}$

18. CMV infection must be verified in severe UC, which does not respond to intravenous corticosteroids. If infection is found, antiviral treatment (ganciclovir, $5.0-7.5 \mathrm{mg} /$ $\mathrm{kg} / 12$ hour) is recommended (quality of evidence, low or very low; classification of recommendation, strong).

- Level of agreement: strongly agree 36.2\%, agree 61.7\%, uncertain $2.1 \%$, disagree $0 \%$, strongly disagree $0 \%$

In patients with UC treated with immunosuppressive therapy, reactivation of CMV is common. Therefore, if severe UC does not respond to the treatment, CMV infection must be identified. CMV colitis is related with poor prognosis and high risk of colectomy. ${ }^{126,127}$ In a prospective study, the prevalence of CMV infection among patients with severe UC and corticosteroid-resistant UC were $21 \%$ to $34 \%{ }^{128}$ and $32 \%$ to $36 \%,{ }^{129,130}$ respectively. In a Korean multicenter prospective study, the prevalence of CMV infection was $43 \%$ (31/72) among patients with moderate to severe UC and higher at $67 \%(14 / 21)$ among those with corticosteroid-resistant UC. All 17 patients who were corticosteroid responsive did not need antiviral treatment. However, in $79 \%(11 / 14)$ of the patients who were corticosteroid resistant and had CMV infection, remission was induced after the antiviral treatment. ${ }^{131}$ According to the Korean multicenter retrospective study that investigated the long-term prognosis of CMV infection in patients with moderate to severe UC, CMV-positive patients had significantly poor prognosis with high surgery and recurrence rates. ${ }^{132}$ Therefore, if the patient with moderate to severe UC does not respond to corticosteroid, the patients should be evaluated for CMV infection.

Diagnosis can be made through histopathology and immunohistochemistry by using tissue specimens collected from biopsy during sigmoidoscopy. CMV can be diagnosed when the H\&E shows giant cells or intranuclear inclusion body. Diagnosis can also be made based on a positive result in CMV antigen immunohistochemical staining or viral DNA PCR. If a definite diagnosis is made, immunosuppressive therapy should be discontinued and 2 to 3 weeks of 5.0 to 7.5 $\mathrm{mg} / \mathrm{kg}$ ganciclovir treatment twice a day should be started.

19. Intravenous cyclosporine is considered for patients with severe UC that does not respond to intravenous corticosteroid (quality of evidence, low; classification of recommendation, weak).

- Level of agreement: strongly agree 6.1\%, agree 71.4\%, uncertain $20.4 \%$, disagree $2.1 \%$, strongly disagree $0 \%$

20. Colectomy is considered if a patient with intravenous corticosteroid-refractory severe UC presents aggravation of clinical symptoms or does not respond to infliximab or cyclosporine treatment (quality of evidence, moderate; classification of recommendation, strong).

- Level of agreement: strongly agree 50.0\%, agree 47.6\%, uncertain $0 \%$, disagree $2.4 \%$, strongly disagree $0 \%$

Intravenous cyclosporine is effective for patients with severe UC, which does not respond to steroids. According to a small-scale RCT ( $n=20), 82 \%$ of patients who failed to respond to intravenous corticosteroid treatment showed response to $4 \mathrm{mg} / \mathrm{kg} /$ day intravenous cyclosporine within a mean treatment duration of 7 days. By contrast, none of the patients in the placebo treatment group showed response (RR, 0.18; 95\% CI, $0.05-0.64 ; P<0.001) .{ }^{130}$ In a study that compared the administration dosage of cyclosporine, 73 patients who failed to respond to steroid treatment were randomly assigned to cyclosporine $4 \mathrm{mg} / \mathrm{kg}$ and $2 \mathrm{mg} / \mathrm{kg}$ groups. ${ }^{131}$ No difference in response rate was found on the 8th day of treatment (83\% vs. $82 \%$ ); however, a higher prevalence of hypertension was found in the $4 \mathrm{mg} / \mathrm{kg}$ group. Therefore, the currently recommended dosage is $2 \mathrm{mg} / \mathrm{kg}$.

According to controlled studies and observational studies, $76 \%$ to $85 \%$ of patients responded to intravenous cyclosporine treatment and avoided colectomy in a short-term period. ${ }^{130-134}$ However, a Cochrane review concluded that no clear evidence suggests that cyclosporine is more effective 
than the standard treatment, as studies are limited by small sample sizes and no long-term results. ${ }^{135}$ In addition, cyclosporine is not often clinically used because of its potential adverse effects and unfavorable long-term clinical outcomes in terms of surgery rate. The colectomy rate among patients responsive to cyclosporine was $20 \%$ after 1 year of treatment and $69 \%$ after 5 years of treatment. ${ }^{134,136}$ According to a retrospective analysis of long-term surgery rates after intravenous cyclosporine therapy for severe UC, the factors to avoid colectomy were a successful switching the treatment to oral thiopurine and naiveness to thiopurine prior cyclosporine therapy. ${ }^{134,137-139}$ Therefore, if the patient is unresponsive or have a failed past thiopurine treatment, cyclosporine treatment may not be a good option.

The adverse effects of cyclosporine are hypertension, vomiting, hypokalemia, and hypomagnesemia. Caution should be exercised when using cyclosporines for hypocholesterolemia because grand mal seizure has been reported.

Tacrolimus is a calcineurin inhibitor that works through the same mechanism as does cyclosporine. It showed superior effect to placebo therapy in a RCT in severe UC patients. ${ }^{140}$ The response rates were $67 \%$ and $50 \%$ when the trough levels were 10 to $15 \mathrm{ng} / \mathrm{mL}$ and 5 to $10 \mathrm{ng} / \mathrm{mL}$, respectively, and $18 \%$ in placebo treatment. The weakness of this study is that the number of patients was too small. However, response to tacrolimus was similar with that response to 0.1 to $0.2 \mathrm{mg} / \mathrm{kg}$ oral cyclosporine and 0.01 to $0.02 \mathrm{mg} /$ $\mathrm{kg}$ intravenous cyclosporine in other case series. ${ }^{67,131,139}$ The long-term colectomy rate was $57 \%$ among the patients with UC treated with tacrolimus for 44 months. ${ }^{141}$

If the patient is not responsive to $\geq 3$ days of intravenous corticosteroid therapy and to the subsequent 5 to 7 days of intravenous cyclosporine or infliximab therapy, surgery must be considered. Poor prognosis such as surgical complications or higher mortality rate during admission is related to delayed surgery in patients with severe UC. According to a study that analyzed data from a database of admitted patients around the United States, patients with severe UC who had surgery within 3 days of admission had lower mortality rate than those who had surgery after 6 days (OR, 2.12; 95\% $\mathrm{CI}, 1.13-3.97)$ or 11 days $\left(\mathrm{OR}, 2.89\right.$; 95\% CI, 1.41-5.91). ${ }^{142}$

\section{3) Anti-tumor Necrosis Factor Therapy}

21. Patients with infection should not receive biological therapy until the infection is controlled. Abscess must be drained before using biologics. Latent infections such as tuberculosis, hepatitis B, and human immunodeficiency virus must be excluded or treated before starting biological therapy. Patients inoculated with live vaccines should not receive biological therapy for 3 months (quality of evidence, very low; classification of recommendation, weak).

- Level of agreement: strongly agree 26.1\%, agree 65.2\%, uncertain 6.5\%, disagree 2.2\%, strongly disagree $0 \%$

Anti-TNF therapy increases the risk of severe infection in patients with rheumatic arthritis; however, the evidence is relatively poor in patients with IBD. ${ }^{143,144}$ The ACT- 1 and ACT-2 studies, which are important studies about the effect of infliximab in patients with UC, showed no significant evidence of serious infection risk related with anti-TNF therapy. ${ }^{90}$ However, meta-analysis reported that anti-TNF therapy raises the risk of opportunistic infection almost twice higher in patients with IBD. The risk increases when the patients received immunomodulators concomitantly. ${ }^{124}$

If the patient has active infection, anti-TNF therapy must be temporarily discontinued until the infection is controlled. In addition, $C$. difficile infection must be excluded before starting anti-TNF therapy because it is related to higher risks of admission and mortality rate. ${ }^{145}$ The risk of pneumococcal infection is also increased in IBD patients with immunosuppressive therapy and the risk is higher in patients with advanced age or comorbidity. Therefore, pneumococcal vaccination in advance is recommended for IBD patients receiving anti-TNF therapy. ${ }^{20}$

Anti-TNF therapy is related with pneumocystis infection, and the risk is higher in patients with advanced age, underlying pulmonary disorders, or concomitant use of highdose corticosteroid. ${ }^{146}$ Prophylactic administration of cotrimoxazole is recommended if the patient is treated with triple immunosuppressants, including calcineurin inhibitors or anti-TNF agents. Co-trimoxazole administration should be also considered when the patient receives two kinds of immunosuppressants, including a calcineurin inhibitor. Cotrimoxazole is administered 80 to $400 \mathrm{mg}$ once a day or 160 to $800 \mathrm{mg}$ three times a week. ${ }^{145}$ Attenuated influenza vaccination should also be performed before or during the antiTNF therapy. When the patient has influenza, early antiviral treatment must be started. ${ }^{20}$

Anti-TNF therapy can reactivate latent tuberculosis. ${ }^{147}$ Therefore, diagnosis and treatment of latent tuberculosis are important before starting anti-TNF therapy. To diagnose active and latent tuberculosis, history taking, physical examination, chest radiography, and tuberculosis infection test must be performed. All patients must go through chest radiography to exclude asymptomatic active tuberculosis before 
receiving anti-TNF agents. Fibrostreaky lesions on chest radiography should be considered as spontaneous remission of tuberculosis, and treatment for latent tuberculosis must be initiated regardless of the tuberculosis infection result. However, when only small calcific nodules are observed on chest radiography, treatment for latent tuberculosis is unnecessary because of the low risk of live bacteria. ${ }^{148}$ If the patient had received adequate treatment for tuberculosis, treatment is not necessary regardless of fibrotic lesions. ${ }^{149}$

Tuberculin skin test (TST) and interferon- $\gamma$ release assay (IGRA) are tests to detect tuberculosis infection. Diagnosis of latent tuberculosis in patients receiving anti-TNF follows the guidelines for immunosuppressed patients. Diagnosis can be made by using IGRA alone or in combination with TST. TST alone cannot be used as a diagnostic tool for latent tuberculosis.

In patients with active tuberculosis, anti-TNF therapy can be recommended after completion of tuberculosis treatment. However, if the disease is a drug-sensitive tuberculosis with mild activity, anti-TNF therapy can be considered after 2 months of intensive treatment. In case of latent tuberculosis, anti-TNF therapy is usually recommended after 3 weeks of treatment; however, anti-TNF therapy can also be considered at the initial time of tuberculosis treatment. The standard regimen for latent tuberculosis is 9 months of isoniazid. However, 4 months of rifampicin therapy or 3 months of isoniazid/rifampicin combination therapy can be also recommended. ${ }^{103}$

Use of corticosteroids, immunomodulators, or anti-TNF therapy was related with hepatic dysfunction in $25 \%$ to $36 \%$ of patients with IBD and HBV infection, and more than half of the patients with HBV reactivation showed hepatic failure. ${ }^{150,151}$ Therefore, baseline studies for HBV infection, including HBsAg, anti-HBsAb, and anti-HBcAb, must be performed at the time of diagnosis. If $\mathrm{HBV}$ infection is confirmed, HBeAg, anti-HBeAb, and HBV-DNA tests must be performed. When both anti-HBsAb and anti-HBcAb are negative, vaccination should follow. ${ }^{145}$

Patients with IBD show decreased response to $\mathrm{HBV}$ vaccination, which may be related with the disease itself and use of anti-TNF agents. Therefore, anti-HBsAb level must be assessed after vaccination, and antibody titer should be monitored in the high-risk group. The standard dose of vaccination may be insufficient in patients with IBD who were not previously vaccinated and are especially being treated with anti-TNF therapy. Repeated vaccination with double dose in 0,1 , and 2 months can be given to the patient when no antibody is detected after the first vaccination schedule. ${ }^{152}$
Prophylactic antiviral treatment using nucleotide/nucleoside analogue is recommended in HBsAg-positive patients at least 2 weeks before immunosuppressive therapy and until 12 months after its termination. The presence of anti$\mathrm{HBcAb}$ and absence of HBsAg may be suggestive of latent infection. However, reactivation of the HBV during the immunosuppressive therapy is rare. Antiviral therapy is not necessary until HBV-DNA is detected. HBV-DNA should be checked every 2 to 3 months.

22. When starting anti-TNF therapy, combination therapy with thiopurine or methotrexate (MTX) rather than antiTNF monotherapy is recommended to induce remission (quality of evidence, moderate for AZA and very low for MTX; classification of recommendation, strong).

- Level of agreement: strongly agree 15.2\%, agree 69.6\%, uncertain 10.9\%, disagree 4.4\%, strongly disagree $0 \%$

Effect of anti-TNF and AZA combination therapy was proved in the UC SUCCESS study. In anti-TNF-naive patients with moderate to severe UC, the remission rate without corticosteroid on the 16 weeks was higher in the combination therapy group with $39.7 \%$ than in the infliximab monotherapy group with $23.7 \% .^{95}$ However, the mucosal healing rate and improvement of partial or total Mayo score were similar in both groups. In the ULTRA 1 study, the patients in the combination therapy group, who received adalimumab and immunomodulators without corticosteroid, showed the best therapeutic effect. ${ }^{92}$ The ULTRA 2 study revealed that antibody to adalimumab was detected less frequently in the combination therapy group than in the monotherapy group. ${ }^{93}$ In the PURSUIT study, although combination therapy with immunomodulator decreased the incidence of antibody to golimumab, no significant association was found between the serum golimumab level and the therapeutic effect. $^{94}$

Experts concluded that combination therapy is preferred for thiopurine-naive patients when starting anti-TNF agents. However, the effect of combination therapy is not clear in patients unresponsive to previous thiopurine therapy. ${ }^{139}$ Studies on the maintenance period of combination therapy are still insufficient. ${ }^{24}$ When the immunomodulator was withdrawn during the combination therapy, the factors associated with recurrence were higher levels of inflammatory markers, mucosal inflammation on endoscopic examination, shorter period of remission, and undetectable anti-TNF trough level. ${ }^{153}$

Although IBD itself does not increase the risk of infection, use of anti-TNF agents or thiopurine can increase the risk, 
which can further increase with combination therapy. ${ }^{24}$ The occurrence rates of nonmelanoma skin cancer and other cancers are not increased by anti-TNF therapy. However, considering that the incidence is increased in combination therapy, the increased risk of cancer is more likely due to administration of immunomodulators. ${ }^{154}$ Especially patients aged $>65$ years have a higher risk of severe infection or lymphoproliferative disorders, ${ }^{136,137}$ whereas patients aged $<35$ years who received thiopurine therapy for $\geq 2$ year usually developed hepatosplenic T-cell lymphoma. ${ }^{138}$ By extrapolating the results of the study on rheumatoid arthritis, using MTX instead of AZA can be recommended in elderly patients, who have higher risks of developing nonmelanoma skin cancer and lymphoma. ${ }^{155}$

23. Evaluation of treatment response is recommended after 8-12 weeks of anti-TNF therapy to determine the need to modify therapy (quality of evidence, low; classification of recommendation, strong).

- Level of agreement: strongly agree $42.6 \%$, agree 57.5\%, uncertain $0 \%$, disagree $0 \%$, strongly disagree $0 \%$

24. Anti-TNF dose escalation is recommended for remission induction when no sufficient response is achieved. Shortening the infusion interval of infliximab or elevating the dose to $10 \mathrm{mg} / \mathrm{kg}$ is recommended. The injection frequency of adalimumab is shortened to 1 week (quality of evidence, very low; classification of recommendation, strong).

- Level of agreement: strongly agree 25.6\%, agree 58.1\%, uncertain $16.3 \%$, disagree $0 \%$, strongly disagree $0 \%$

In the RCTs that were assessed every 2 weeks after initiation of treatments, significant symptomatic improvement was reported as early as 2 to 4 weeks with anti-TNF therapy. ${ }^{92-94}$ The research that compared the effect of anti-TNF therapy with that of placebo treatment for remission induction showed significantly higher remission rate with antiTNF therapy usually in the eighth week of treatment. ${ }^{90,92-94}$ In the ULTRA 2 study, the symptom remission rate with adalimumab treatment was highest on the 16 weeks and started declining thereafter. ${ }^{93}$ Therefore, 8 to 12 weeks is an adequate period to assess the treatment effect of anti-TNF therapy. If no response is observed, the therapy should be modified. However, if the UC is severe, early assessment must be considered. However, no data on the optimum period of endoscopic assessment are available yet.

Before determining the initial failure of the treatment in patients showing insufficient response to anti-TNF therapy, increasing the dosage must be considered first. The associations of high blood anti-TNF agent level with high remission and maintenance rates ware proved in RCTs. ${ }^{156}$ Moreover, high trough level was associated with high mucosal healing rate. ${ }^{157,158}$ The methods of drug dose elevation for remission induction include increasing the dose and shortening the admission period.

\section{4) Other Biological Therapies}

25. In patients who have primary nonresponse in remission induction with anti-TNF, vedolizumab treatment may be more effective than switching to another anti-TNF agent (quality of evidence, very low; classification of recommendation, weak).

- Level of agreement: strongly agree 2.0\%, agree 73.5\%, uncertain $20.4 \%$, disagree $4.1 \%$, strongly disagree $0 \%$

26. In patients with loss of secondary response to antiTNF, different types of anti-TNF agents or vedolizumab treatment is recommended based on therapeutic drug monitoring (quality of evidence, very low; classification of recommendation, strong).

- Level of agreement: strongly agree 17.4\%, agree 73.9\%, uncertain $6.5 \%$, disagree $2.2 \%$, strongly disagree $0 \%$

27. Vedolizumab is considered for remission induction when moderate to severe UC fails to respond to corticosteroids, thiopurine, or anti-TNF (quality of evidence, moderate; classification of recommendation, strong).

- Level of agreement: strongly agree 4.4\%, agree $80.4 \%$, uncertain $10.9 \%$, disagree $4.4 \%$, strongly disagree $0 \%$

28. Evaluation of treatment response is recommended after 8-14 weeks of vedolizumab therapy to determine the need to modify therapy (quality of evidence, very low; classification of recommendation, strong).

- Level of agreement: strongly agree $26.7 \%$, agree $71.1 \%$, uncertain 2.2\%, disagree 0\%, strongly disagree 0\%

Dose escalation is the first strategy to consider in patients with inadequate response to anti-TNF therapy. This should be decided based on therapeutic drug monitoring. Studies are lacking on whether to change the treatment to other antiTNF agents or to vedolizumab in patients who have failed to respond despite the dose elevation. According to studies, changing the type of anti-TNF agent can be more effective for patients who test positive for antidrug antibody. When the patient has a history of primary nonresponse, it will be less effective. ${ }^{157,159,160}$

A recent study showed that in patients with primary nonresponse to anti-TNF therapy, changing the treatment to vedolizumab had better long-term result than changing the type of anti-TNF agent. In a study of 99 patients with primary nonresponse to infliximab and no history of receiving other anti-TNF medications, the patients who received vedolizumab showed numerically lower cumulative recurrence rate 
(log-rank, $P=0.080)$ than those who changed to a different anti-TNF agent. ${ }^{161}$

As vedolizumab works in a different mechanism with anti-TNF medication, it can be effective for patients with either primary or secondary anti-TNF therapy failure. In the GEMINI I study, 374 patients who used corticosteroid, immunomodulator, or anti-TNF agent in the past were randomized into the vedolizumab or placebo group. ${ }^{162}$ On the 6 weeks of treatment, vedolizumab showed a significantly higher remission rate than placebo $(16.9 \%$ vs. $5.4 \% ; P=0.001)$. When the result was analyzed by dividing them further into groups according to the previous medications, no statistically significant difference was found, but vedolizumab showed numerically better remission rate: anti-TNF (9.8\% vs. $3.2 \%$ ), corticosteroids ( $21.4 \%$ vs. $0 \%$ ), or immunomodulators (21.9\% vs. $10.9 \%) .{ }^{162}$ Clinical response rate was significantly higher in the vedolizumab group ( $47.1 \%$ vs. $25.5 \%$; $P<0.001)$. The clinical response rate of vedolizumab was also higher in the groups that had treatment failure with anti-TNF agents (39.0\% vs. $20.6 \%)$ or corticosteroids (59.5\% vs. $20.0 \%){ }^{162}$ Mucosal healing rate was higher in the vedolizumab group than in the placebo group (59.5\% vs. $24.0 \%)$ among the patients who had failed corticosteroid treatment. ${ }^{162}$ In phase 2 RCT, the clinical response rate of the vedolizumab group was approximately twice that of the placebo group ( $>50 \%$ vs. $22 \%-33 \%){ }^{163}$ No significant difference in the proportion of patients who experienced more than one adverse event during the remission induction treatment was found between the vedolizumab and placebo groups ( $40 \%$ vs. $46 \%$ ). However, the vedolizumab group had a lower proportion of patients who experienced severe adverse events ( $2 \%$ vs. $7 \%) .{ }^{162}$ The most common adverse events associated with vedolizumab treatment were headache, aggravation of UC, and infection. Therefore, vedolizumab therapy can be a useful treatment option for patients with failed corticosteroid, immunomodulator, or anti-TNF therapy. No studies have been conducted on the treatment strategy after vedolizumab treatment failure, but anti-TNF agents can be considered. In the GEMINI I study, no significant differences were found between 4 - and 8 -week treatment intervals in vedolizumab maintenance treatments. ${ }^{162}$

In the GEMINI I study, vedolizumab treatment showed significantly higher symptomatic response rate on the 6 weeks of treatment than placebo treatment ( $47.1 \%$ vs. $25.5 \%$; 95\% CI, 11.6-31.7; $P<0.001) .{ }^{162}$ Improvement of partial Mayo score was highest on the 6 weeks. Thereafter, no further improvement in Mayo score was observed, and a similar effect continued during the maintenance treatment period. There- fore, assessment of vedolizumab treatment is recommended in the 8th-14th week, which is before the start of the maintenance treatment.

\section{Other Treatments}

\section{1) Methotrexate}

Prospective studies on the effect of MTX on UC are lacking, and the results are not consistent because of the variance of medication dosages or administrating methods. ${ }^{164-166}$ According to a RCT, the effect of MTX therapy was not superior to that of placebo treatment in steroid-dependent patients when used at $12.5 \mathrm{mg}$ per week by oral administration. ${ }^{164} \mathrm{~A}$ Cochrane review concluded that evidence is insufficient to recommend MTX therapy to UC patients. ${ }^{166}$

\section{2) Probiotics}

Evidences are inadequate to support the use of probiotics in UC treatment. In a meta-analysis of 23 RCTs that investigated the effect of probiotics on UC, CD, and pouchitis, the remission rate in the probiotics group was higher than that in the placebo group (RR, $1.80 ; P<0.0001)$. However, the result of the subgroup analysis showed a significant effect only in VSL\#3 (RR, 1.74; $P=0.004) .{ }^{167}$ In a meta-analysis of three RCTs that investigated VSL\#3 effects on UC, the group that received additional VSL\#3 in the conventional therapy showed a higher remission rate than the group that received the conventional therapy alone (43.8\% vs. $24.8 \%$ : OR, 2.4 ; 95\% CI, 1.48-3.88; $P=0.0001) .{ }^{168}$ However, the quality of the studies included in the meta-analysis was not good enough. Therefore, it is difficult to recommend probiotics as remission induction treatment for UC.

In a meta-analysis of RCTs about the effect of Escherichia coli (E. coli) Nissle 1917 on UC, it did not show better effect on remission induction than placebo but showed a similar effect on remission maintenance with the 5-ASA treatment. ${ }^{167,169,170}$ Therefore, when 5-ASA cannot be used for remission maintenance treatment because of its adverse effect, $E$. coli Nissle 1917 can be considered as the alternative treatment.

\section{MAINTENANCE OF REMISSION}

The goal of maintenance therapy for patients with UC is to maintain clinical and endoscopic remission without using corticosteroids. In addition, it is aimed at controlling the symptoms, improving patients' quality of life, and preventing colon cancer development and improving its long-term 
prognosis.

According to a recent meta-analysis of RCTs, among the patients with UC who are in inactive or remission status, $60 \%$ of the nontreated patients had a disease relapse regardless of the extent of the disease. ${ }^{171}$ Therefore, remission maintenance therapy is recommended to all patients with UC. Things to consider when choosing the treatment for remission maintenance are extent and activity of the disease, safety of the treatment agents, and prevention of colon cancer. Frequency of recurrence, medications used at the recent relapse, and adherence to the medications must also be considered in maintenance therapy. ${ }^{172}$

\section{5-Aminosalicylic Acids}

29. Oral 5-ASA is recommended as the first-line maintenance therapy in patients who respond to oral/topical 5-ASA or corticosteroids (quality of evidence, high; classification of recommendation, strong).

- Level of agreement: strongly agree $68.9 \%$, agree $31.1 \%$, uncertain $0 \%$, disagree $0 \%$, strongly disagree $0 \%$

30. Topical 5-ASA (suppository or enema) can be used as maintenance therapy for proctitis or left-sided colitis (quality of evidence, high; classification of recommendation, strong).

- Level of agreement: strongly agree $60.9 \%$, agree $37.0 \%$, uncertain 2.2\%, disagree $0 \%$, strongly disagree $0 \%$

31. Combination therapy is more effective than oral or topical 5-ASA monotherapy. In case of recurrence with oral or topical 5-ASA monotherapy, combination therapy is recommended (quality of evidence, moderate; classification of recommendation, strong).

- Level of agreement: strongly agree $67.4 \%$, agree $32.6 \%$, uncertain $0 \%$, disagree $0 \%$, strongly disagree $0 \%$

32. At least $2 \mathrm{~g} /$ day of oral 5 -ASA is recommended for maintenance of remission (quality of evidence, moderate; classification of recommendation, strong).

- Level of agreement: strongly agree $35.6 \%$, agree $62.2 \%$, uncertain $0 \%$, disagree $2.2 \%$, strongly disagree $0 \%$

33. The 5-ASA dose can be adjusted for maintenance of remission based on the case. High-dose oral 5-ASA therapy $(\geq 3.0 \mathrm{~g} /$ day) can be useful in patients such as extensive colitis or frequent relapse (quality of evidence, low; classification of recommendation, weak).

- Level of agreement: strongly agree 19.6\%, agree 73.9\%, uncertain 6.5\%, disagree $0 \%$, strongly disagree $0 \%$

34. In patients with topical 5-ASA-induced remission, the same therapy can be used to maintain remission. It can also be used by divided dosing of $3 \mathrm{~g}$ of topical 5-ASA per week (quality of evidence, very low; classification of recommendation, weak).

- Level of agreement: strongly agree $18.4 \%$, agree $77.5 \%$, uncertain $4.1 \%$, disagree $0 \%$, strongly disagree $0 \%$
35. The effects of taking oral 5-ASA once a day and taking the same dosage with frequent administration are similar for maintenance of remission. Therefore, dosing frequency can be determined according to the patients' preference and compliance (quality of evidence, high; classification of recommendation, strong).

- Level of agreement: strongly agree $44.9 \%$, agree $55.1 \%$, uncertain $0 \%$, disagree $4.6 \%$, strongly disagree $0 \%$

Oral 5-ASA is the first-line maintenance therapy for patients who respond to oral/topical 5-ASA or corticosteroids, and various studies have reported that oral 5-ASA is an effective maintenance therapy. ${ }^{173-179}$

A meta-analysis of 11 RCTs showed that the relative risk of recurrence was significantly lower in patients treated with 5-ASA than in those treated with placebo $(0.65 ; 95 \% \mathrm{CI}$, 0.55-0.76) among patients with quiescent UC. ${ }^{59}$ In addition, a meta-analysis of seven clinical trials also showed that the recurrence rate was lower in the 5-ASA maintenance group with $41 \%$ than in the placebo group with $58 \%$ (RR, $0.69 ; 95 \%$ CI, 0.62-0.77) ${ }^{171}$ However, no significant difference in the incidence of adverse event was found between the oral 5-ASA and placebo groups. Topical 5-ASA (suppository or enema) are effective for maintenance of remission in proctitis or left-sided colitis. A meta-analysis of seven RCTs showed a significantly lower relative risk of relapse in the topical 5-ASA group (6-24 months) than in the placebo group $(0.60,95 \%$ CI, 0.49-0.73). ${ }^{180}$ In addition, in a meta-analysis of four RCTs, the 12-month clinical remission rate in the topical 5-ASA group was significantly higher than that in the placebo group (62\% vs. 30\%; RR, 2.22; 95\% CI, 1.26-3.90; $P<0.01$ ). ${ }^{181}$ A recent meta-analysis also reported that 5-ASA had significantly lower rates of clinical or endoscopic remission failure (OR, 0.47; $95 \%$ CI, $0.36-0.62$ with a number needed to treat of 6$){ }^{173}$

RCTs have been conducted on combination therapy with oral and topical 5-ASA. Remission maintenance rate was significantly higher in the combination therapy group than in the oral 5-ASA only group. ${ }^{38,182}$ Therefore, combination therapy can be considered for relapse with oral or topical 5-ASA monotherapy.

Ten RCTs compared two or three different dosages of oral 5-ASA for maintenance therapy. ${ }^{67,140,172,179,183-188}$ In three studies, remission maintenance rates (recurrence rates) did not significantly differ according to dosage ${ }^{67,140,186}$ but seven studies showed significant differences between dose groups. ${ }^{172,179,183-185,187,188}$ Each study varied in maximum oral 5-ASA dosage, from 1.2 to $4.8 \mathrm{~g} /$ day. Among six studies that used $\geq 2.0 \mathrm{~g} /$ day of oral 5-ASA as maximum dosage, five showed better effect in the higher-dose group, ${ }^{67,172,179,183,186,187}$ 
three studies used $\geq 3.0 \mathrm{~g} /$ day of oral 5-ASA as maximum dose. When this dose was compared with 5-ASA doses of $1.5,1.5$, and $2.4 \mathrm{~g} /$ day, respectively, two studies showed significantly higher remission maintenance rate $(P<0.05)$ and one study showed a higher tendency in the high-dose group $(P=0.057) .{ }^{178,182,186}$ In another study, when the patients had mild inflammation on the endoscopic finding at the start of the maintenance therapy, high-dose ( $3.0 \mathrm{~g} /$ day vs. $1.5 \mathrm{~g}$ /day) therapy was found to be more effective. ${ }^{179}$ In yet another study, high-dose ( $4.8 \mathrm{~g} /$ day vs. $2.4 \mathrm{~g} /$ day) treatment showed better effect when used for extensive colitis, young patients aged $<40$ years, or patients with frequent relapses. ${ }^{187}$ Therefore, using an oral 5-ASA dosage of $\geq 2.0 \mathrm{~g}$ /day for remission maintenance is recommended, and using a high dosage of $\geq 3 \mathrm{~g} /$ day for maintenance therapy can be useful for patients with extensive colitis or frequent relapses. The use of high-dose 5-ASA did not significantly increase the incidence of adverse events when compared with low or standard doses. ${ }^{67,140,172,179,183-188}$

Previous studies reported that taking oral 5-ASA once a day and taking the same dose twice or three times a day had a similar effect on remission maintenance. ${ }^{68,175,179,189}$ In addition, a meta-analysis of seven RCTs showed no significant difference in recurrence rate (RR, 0.94; 95\% CI, 0.82-1.08) ${ }^{59}$ and adverse effect between once-daily dosing and divided dosing ${ }^{58,66,184}$ Several studies have reported no significant differences in adherence between oral 5-ASA once-daily dosing and divided dosing ${ }^{58,59,66,184}$ However, a recent study with 362 patients who received oral 5-ASA reported that the 1-year remission rate was $12 \%$ higher in the once-daily dosing group than in the twice-daily divided dosing group $(73.8 \%$ vs. $63.6 \%$ ). Adherence to the medication was significantly higher in the patients who received once-daily dosing than in those who received divided dosing. ${ }^{189}$ In addition, other studies reported that taking oral 5-ASA in once-daily dosing is more preferred by patients than taking it in divided dosing for remission maintenance. ${ }^{67,68}$

\section{Thiopurines}

36. AZA or 6-MP is recommended to patients with UC with early or frequent relapses, who are unable to take 5-ASA, or who are already taking adequate dosage of 5-ASA (quality of evidence, very low; classification of recommendation, weak).

- Level of agreement: strongly agree 15.6\%, agree 73.3\%, uncertain $11.1 \%$, disagree $0 \%$, strongly disagree $0 \%$

37. In patients with UC who showed clinical remission with corticosteroid, thiopurine therapy can be used to maintain remission without corticosteroids (quality of evidence, low; classification of recommendation, weak).

- Level of agreement: strongly agree 19.6\%, agree 63.0\%, uncertain 15.2\%, disagree 2.2\%, strongly disagree 0\%

38. Thiopurine is recommended to patients with corticosteroid-dependent UC (quality of evidence, high; classification of recommendation, strong).

- Level of agreement: strongly agree 48.7\%, agree 51.4\%, uncertain $0 \%$, disagree $0 \%$, strongly disagree $0 \%$

39. Thiopurine is recommended to maintain remission when cyclosporine or tacrolimus was used for remission induction (quality of evidence, low; classification of recommendation, weak).

- Level of agreement: strongly agree 14.3\%, agree 77.5\%, uncertain $8.2 \%$, disagree $0 \%$, strongly disagree $0 \%$

AZA or 6-MP can be effective for patients who are unresponsive to or intolerant of 5-ASA, or are corticosteroid dependent. ${ }^{24}$ AZA or 6-MP should be considered for remission maintenance when $>2$ episodes of disease flare up requiring corticosteroid treatment for 12 months or when 5-ASA cannot maintain the remission state. AZA or 6-MP can be used initially to maintain remission in severe UC, and 5-ASA can be used if either medication is contraindicated. ${ }^{109}$ Metaanalysis studies reported that AZA is effective in remission maintenance of UC patients. ${ }^{190-192}$ Sixty-five percent of patients failed to maintain remission with the placebo, whereas $44 \%$ of patients failed with AZA treatment. ${ }^{192}$

An RCT showed that AZA was significantly more effective than 5-ASA in maintaining clinical and endoscopic remission and avoiding corticosteroid requirement for a 6-month follow-up period in the treatment of steroid-dependent UC (53\% vs. $21 \%) .{ }^{80}$ A Korean study also showed that the 3-year remission maintenance rate in corticosteroid-dependent UC patients was $25.0 \%$ in the AZA-intolerant group and $71.2 \%$ in the AZA-treated group. ${ }^{193}$

Calcineurin inhibitors such as cyclosporine or tacrolimus can be used as salvage therapy for corticosteroid-refractory patients with UC. ${ }^{194}$ AZA or 6-MP is more effective than 5-ASA monotherapy in maintaining remission and preventing colectomy when cyclosporine was used for remission induction in patients with severe corticosteroid-refractory UC. ${ }^{133,195-197}$ In a retrospective study, colectomy is required in $45 \%$ of the patients in the cyclosporine monotherapy group and only $20 \%$ of the patients in the AZA or 6-MP group among initial cyclosporine responders. ${ }^{133}$ Oral cyclosporine is usually used until thiopurines show effects, but switching to thiopurines without using oral cyclosporine is another option. ${ }^{198}$ Oral cyclosporine is generally not used for $>6$ months because of the long-term adverse effect such as nephrotoxicity. 
The recommended dose of AZA is 2.0 to $2.5 \mathrm{mg} / \mathrm{kg} / \mathrm{day}$, and that of 6-MP is 1.0 to $1.5 \mathrm{mg} / \mathrm{kg} / \mathrm{day}^{98,199}$ One of the most important limitations and serious adverse effects of thiopurines is leukopenia. Leukopenia occurs only in 5\% of Caucasians. ${ }^{200-202}$ However, it is more common in Asians. According to a Korean multicenter study, among 278 patients who received a mean AZA dosage of $1.8 \mathrm{mg} / \mathrm{kg} /$ day, 110 (39.6\%) developed leukopenia. ${ }^{203}$ Two Japanese studies that used cohorts with wild-type TPMT (thiopurine S-methyltransferase) genes showed that leukopenia developed in 18 of 114 patients (15.8\%) and 7 of 70 patients $(10.0 \%)$ even though only AZA $50 \mathrm{mg} /$ day was administered. ${ }^{204,205}$ A Chinese study also showed that 36 of 199 patients (18.1\%) developed leukopenia $\left(<3,500 / \mathrm{mm}^{3}\right) .{ }^{206}$ Considering that most of East-Asian studies used lower doses of AZA than recommended, more frequent and severe leukopenia is expected with the standard dose of thiopurines. ${ }^{24}$

A stepwise increase in thiopurine dose for several months is usually preferable to starting with the target dose in EastAsians. ${ }^{24}$ The best way to reach the target dosage is not known yet. However, starting from $50 \mathrm{mg}$ and increasing the dosage by 25 mg every 2 to 4 weeks while monitoring adverse effects such as leukopenia is commonly used. Based on the survey of clinical practice patterns in the treatment of IBD in Korea, $80 \%$ of the responders started AZA therapy at $50 \mathrm{mg}$ /day, $68 \%$ increased the dose by $25 \mathrm{mg}$, and $56 \%$ increased the dose every 4 week. ${ }^{15}$ However, it may delay the time to clinical response, although thiopurine-induced myelotoxicity can be decreased. ${ }^{207}$

Assessment of the TPMT genotype or enzyme activity before using thiopurines has limited value in East-Asian patients. The TPMT mutation rate is lower in Asians (1\%-3\%) than in Caucasians $(10 \%)$. Nevertheless, Asian patients show a higher incidence of thiopurine-induced leukopenia. Among Asians who show thiopurine-induced leukocytopenia, the percentage of those with TPMT mutation is only $0 \%$ to $5.6 \%{ }^{24}$ Assessment of the NUDT15 (nucleoside diphosphate-linked moiety X motif 15) genotype may be more useful in predicting thiopurine-induced early leukopenia. In Koreans, a nonsynonymous single-nucleotide polymorphism of the NUDT15 gene mutation was found to be a risk factor of thiopurine-induced early leukopenia. The frequency of the NUDT15 risk allele is much higher in East Asians (Koreans, 10.4\%; Japanese, 7\%; Chinese, 13\%; and admixed American population, $2 \%) .{ }^{208}$

Monitoring of complete blood count is necessary for all patients with UC treated with thiopurines. Severe leukopenia usually occurs at the early phase of the treatment. ${ }^{209}$ According to a study, the incidence of severe leukopenia $(<1,000 /$ $\mathrm{mm}^{3}$ ) was highest within the first 8 weeks of thiopurine therapy and the median time to first documentation of severe leukopenia was 24.5 days. ${ }^{210}$ No consensus has been reached on the optimal frequency of complete blood count tests. ${ }^{141} \mathrm{How}$ ever, monitoring once every 2 weeks for the first 2 months and then every 4 to 12 weeks is a preferred schedule. ${ }^{24}$

Bone marrow toxicity must be cautioned when thiopurine is combined with oral 5-ASA. Combination therapy with 5-ASA and thiopurines increases the serum level of 6-thioguanine, ${ }^{211,212}$ which is the active metabolite of thiopurines. The combination therapy has a higher rate of myelotoxicity compared with thiopurine monotherapy. ${ }^{211,213}$

Evidences are insufficient to determine when thiopurines can be discontinued. ${ }^{24}$ The recurrence rate of UC after cessation of AZA is $35 \%$ to $77 \%$ after 1 year and $65 \%$ to $75 \%$ after 5 years. ${ }^{164,202,214}$ Duration of AZA maintenance was not related to the recurrence rate after treatment cessation, and prolonged or indefinite use of thiopurines may be considered for remission maintenance..$^{202}$ Usually, thiopurine is used for at least 18 months after remission and can be maintained for $\geq 4$ years. ${ }^{24}$ Thiopurines are frequently discontinued because of adverse events such as nausea, hepatotoxicity, myelotoxicity, and pancreatitis. Overall, $10 \%$ to $28 \%$ of patients experience adverse effects, of whom $50 \%$ to $80 \%$ are required to discontinue the medication. ${ }^{165}$

Use of thiopurines increases the risk of lymphoma and nonmelanoma skin cancer, but the absolute risk of malignancy is low. ${ }^{24}$ According to a meta-analysis of eight populationbased studies, the standardized incidence ratio of lymphoma was increased to 5.71 (95\% CI, 3.72-10.1) in patients with UC treated with thiopurine but was 1.42 (95\% CI, 0.86-2.34) in patients who discontinued thiopurine. ${ }^{215}$ In a recent metaanalysis that involved $\geq 60,000$ patients with IBD, the pooled adjusted hazard ratio of nonmelanoma skin cancer after using thiopurines was 2.28 (95\% CI, 1.50-3.45). ${ }^{216}$ However, the result of this meta-analysis should be interpreted carefully because of the marked heterogeneity between the studies. Whether the modestly increased risk of lymphoma and nonmelanoma skin cancer should be considered prior to the benefits of thiopurines in the treatment of IBD is still unclear. $^{216,217}$

\section{Biologics}

40. Anti-TNF therapy is recommended to corticosteroiddependent patients with UC (quality of evidence, very low; classification of recommendation, strong).

- Level of agreement: strongly agree $31.1 \%$, agree 57.8\%, uncertain $8.9 \%$, disagree $2.2 \%$, strongly disagree $0 \%$ 
Patients who require corticosteroid therapy have higher risks of relapse and colectomy than patients who do not need it. ${ }^{183,218,219}$ Considering the adverse events associated with corticosteroid use, the ultimate goal of UC treatment is to maintain the remission state without corticosteroid use. ${ }^{97,98,220}$

Most patients in RCTs of anti-TNF therapy did not respond to corticosteroids or were using corticosteroids at the time of the study. ${ }^{92-94,120}$ In these studies, anti-TNF therapy showed the effect of reducing corticosteroid use. In the ACT- 1 and ACT-2 studies, $60 \%$ of the patients were using corticosteroids at the time of infliximab therapy and 30\% showed resistance to corticosteroids. The infliximab group showed a significantly higher remission rate than the placebo group $(20 \%-30 \%$ vs. $3 \%-10 \%$ at week 30$){ }^{90}$ In addition, the remission rate was similar in both groups regardless of corticosteroid resistance. In the ULTRA 2 study, corticosteroid therapy could be stopped at 16 weeks of treatment in $31 \%$ of the adalimumab therapy group and in $18 \%$ of the placebo group. This effect was maintained through 52 weeks. ${ }^{93}$ In PURSUIT study of maintenance therapy, $54 \%$ of the patients were using corticosteroids at the time of the treatment, and $25 \%$ of the patients in the golimumab group and $18 \%$ of the patients in the placebo group maintained remission without using corticosteroids at 54 weeks of treatment. ${ }^{221}$

AZA therapy can be recommended if the patient has reached clinical remission with corticosteroid therapy. However, in corticosteroid-dependent patients, combination therapy with anti-TNF agent can be a better option. In the SUCCESS study, anti-TNF therapy showed higher a mucosal healing rate than AZA therapy. ${ }^{95}$

41. Continuous anti-TNF therapy is recommended for remission maintenance in patients with remission induced by anti-TNF agents (quality of evidence, very low for infliximab and adalimumab, high for golimumab; classification of recommendation, strong).

- Level of agreement: strongly agree 56.5\%, agree 43.5\%, uncertain $0 \%$, disagree $0 \%$, strongly disagree $0 \%$

In the ACT-1 study, the 1-year remission rate was higher in the infliximab group with $35 \%$ than in the placebo group with $16 \% .{ }^{90}$ In the prolongation study of ACT-1 and ACT, $90 \%$ of the infliximab-responsive patients showed clinical remission maintenance with up to 3 years of therapy. ${ }^{222}$ The cumulative colectomy rate on 54 weeks of treatment in the ACT-1 and ACT-2 studies was $10 \%$ in the infliximab group and $17 \%$ in the placebo group. Infliximab administration showed a $7 \%$ reduction in surgery rate. ${ }^{223}$
The ULTRA 2 study reported a similar result. Among the patients who showed clinical response after 8 weeks of adalimumab administration, the remission rate at 52 weeks of treatment was $31 \% .{ }^{224}$ In a study that analyzed the treatment effect of adalimumab therapy by prolonging the ULTRA 1 study until 52 week, $38.8 \%$ of the patients who showed response in the 8 weeks of treatment maintained complete remission at 52 weeks. ${ }^{225}$ The PURSUIT study randomized the patients who showed response to golimumab induction treatment into golimumab and placebo groups. The group that continued golimumab therapy showed a higher remission rate at 54 weeks of treatment than the placebo group $(23 \%-28 \%$ vs. $15.6 \% ; P=0.004){ }^{221}$

Anti-TNF therapy is associated with an increased risk of opportunistic infection, particularly when used as combination therapy, especially with corticosteroid or immunomodulator. However, the absolute risk is low. ${ }^{124,125,226}$ In a meta-analysis with 22 RCTs, the occurrence of opportunistic infection was higher in the anti-TNF-treated group with $0.9 \%(39 / 4,135)$ than in the placebo-treated group with $0.3 \%$ (9/2,919; RR, 2.05; 95\% CI, 1.10-3.85) in patients with IBD. ${ }^{124}$ Patients with mycobacterium tuberculosis infection $(n=8)$, herpes simplex infection $(\mathrm{n}=8)$, oral or esophageal candidiasis $(n=6)$, herpes zoster infection $(n=6)$, varicella-zoster infection ( $\mathrm{n}=2)$, CMV or Epstein-Barr virus infection $(\mathrm{n}=2)$, and Nocardia infection $(\mathrm{n}=1)$ were included among the patients treated with anti-TNF agents. The risk of tuberculosis infection increased 2.5 times higher in the patients with anti-TNF therapy. ${ }^{124}$ A meta-analysis of 22 RCTs that compared the incidence of malignancy in patients with IBD showed no significant difference between the anti-TNF group with $0.39 \%$ $(16 / 4,135)$ and the placebo group with $0.45 \%(13 / 2,919$; RR, $0.77 ; 95 \%$ CI, $0.37-1.59) .{ }^{226}$ No occurrence of lymphoma was observed in the anti-TNF group, and three patients were diagnosed as having lymphoma in the placebo group. It appears that anti-TNF therapy does not increase the risk of malignancy up to 1 year of use.

No study has been conducted on the difference of clinical effect among anti-TNF agents. Therefore, anti-TNF agents used for remission induction should be continuously used for remission maintenance. ${ }^{90,221,222,224,225}$ Studies about longterm effect of anti-TNF therapy are lacking. Therefore, continuing the therapy until loss of response is recommended. However, the patient should be informed about the risks and safety problems when an anti-TNF agent is used in a combination therapy, especially with corticosteroid or immunomodulator. 
42. To recapture remission, dose escalation of the anti-TNF agent is recommended when the response disappears during the remission maintenance (quality of evidence, very low; classification of recommendation, strong).

- Level of agreement: strongly agree 21.7\%, agree 69.6\%, uncertain $8.7 \%$, disagree $0 \%$, strongly disagree $0 \%$

A secondary loss of response during the anti-TNF maintenance therapy can be the result of inadequate drug levels and may be due to the production of antidrug antibodies. ${ }^{222,227}$ A retrospective study was performed to understand the reasons for the loss of response or partial response. Serum levels of anti-TNF agents were measured in the study. In $45 \%$ of the patients, the serum level of the agent was lower than the needed level. In $17 \%$ of the patients, antibody against the agent was detected ${ }^{159}$ Eighty-six percent of the patients who had subtherapeutic concentrations showed response to the anti-TNF agent when the dosage was increased. However, only $17 \%$ of the patients who had antidrug antibody showed an effect of the drug. In a prospective study with UC patients who had a recurrence during the adalimumab maintenance therapy, $67 \%$ of the patients who tested negative for antidrug antibody and had subtherapeutic antiTNF agent concentrations showed effective response when the medication dosage was increased. However, the patients who had antidrug antibody against the anti-TNF agent and had low trough levels, increasing the anti-TNF agent dosage showed no response. ${ }^{160}$ Even though the study was not about UC, a study on patients with CD who lost response during the infliximab treatment showed that when the infliximab administration interval was shortened from 8 weeks to 4 weeks, $83 \%$ of the patients showed response at 54 weeks of treatment. This showed a relationship between clinical efficacy and serum trough level. ${ }^{158}$ Therefore, before making a decision about anti-TNF treatment failure, increasing the dosage is needed. Moreover, assessing both serum level of the anti-TNF agent and the presence of antibody against the agent can be useful.

43. Therapeutic drug monitoring is recommended to optimize the anti-TNF agent dosage (quality of evidence, low; classification of recommendation, strong).

- Level of agreement: strongly agree $32.6 \%$, agree $63.0 \%$, uncertain $4.4 \%$, disagree $0 \%$, strongly disagree $0 \%$

Studies that used anti-TNF agents reported the negative effect of low trough level and the antibody production on the therapeutic effects. These show the importance of therapeutic drug monitoring when making treatment deci- sions. ${ }^{94,156-158,160,227}$ Therefore, therapeutic drug monitoring needs to include serum trough level assessment and antibody titration of the agent.

In RCTs of maintenance therapy using anti-TNF agents, 3\% of patients treated with golimumab for 1 year and $15 \%$ of the patients treated with infliximab for 3 years showed positive for antidrug antibody. ${ }^{94,222}$ Among the patients with loss of response to anti-TNF therapy, $20 \%$ had antidrug antibody. ${ }^{159,160}$ Even though the antibody reaction can be temporary and does not always relate to negative effects, an association was found with permanent loss of response when the antibody titration was continuously high. ${ }^{227}$

In a study of infliximab maintenance therapy for patients with secondary loss of response, the increased serum trough level after dose intensification was a strong predictive factor of mucosal healing. ${ }^{228}$ In a prospective study that analyzed the effect of therapeutic drug monitoring in patients who have partial or complete loss of response, dose intensification was more effective than changing the type of anti-TNF agent when the serum trough level was low. On the contrary, when antidrug antibody was present, changing the type of anti-TNF agent was more effective. ${ }^{159}$ In a prospective cohort study of patients with secondary loss of response, $90 \%$ of the patients showed treatment failure even with a different type of anti-TNF agent when their serum trough level was high. ${ }^{160}$ Therefore, therapeutic drug monitoring can be useful in making treatment decisions for patients with secondary loss of response.

44. Continuous use of vedolizumab is recommended for remission maintenance in patients with vedolizumabinduced remission (quality of evidence, moderate; classification of recommendation, strong).

- Level of agreement: strongly agree $43.5 \%$, agree $54.4 \%$, uncertain $2.2 \%$, disagree $0 \%$, strongly disagree $0 \%$

In the GEMINI I study, patients who responded to vedolizumab therapy ( $\mathrm{n}=373$ ) were randomized into groups of vedolizumab every 4 weeks, vedolizumab every 8 weeks, and placebo for maintenance treatment. On the 52 weeks of treatment, the vedolizumab groups showed significantly higher remission rates than the placebo group ( $44.8 \%$ and $41.8 \%$ vs. $15.9 \% ; P<0.001) .{ }^{162}$ In a study of patients with failed corticosteroid treatment in the past, vedolizumab therapy showed a significantly higher long-term mucosal healing rate than placebo (60.0\% and $68.4 \%$ vs. $26.9 \%) .{ }^{15}$ No significant difference in effect was found between the groups treated with vedolizumab every 4 and 8 weeks. ${ }^{162}$ In another study, 
when vedolizumab was maintained for up to 78 weeks, $60 \%$ of the patients maintained remission and no specific adverse effect was observed during the long-term period. ${ }^{229}$

Six vedolizumab studies reported no association between vedolizumab treatment and the occurrence of infection or severe adverse events $(n=2,830$; exposure range, $1-1,977$ days). Adverse effects such as severe clostridium infection, sepsis, and tuberculosis infection were rarely found $(\leq 0.6 \%)$, and none of the patients had progressive multifocal leukoencephalopathy. ${ }^{230}$ Clinically meaningful infusion reaction was also rarely found. Infusion reaction that is severe enough to discontinue vedolizumab treatment was found in three patients in the GEMINI 1 study and in one patient in the GEMINI 2 study. Immune response to the agent was also rarely found. According to the GEMINI 1 study, which monitored patients for 52 weeks, among 620 patients, only $3.7 \%$ showed a positive result for antivedolizumab antibody during the remission induction and maintenance periods. In the GEMINI 2 study, the positive result was found in $4.1 \%$ of the patients. If the patient does not have a history of abnormal reaction to vedolizumab therapy, pretreatment with antihistamine, corticosteroid, or acetaminophen is not needed. Combination therapy with an immunomodulator is related with suppression of antibody production on medication. ${ }^{231,232}$ Therefore, combination therapy with vedolizumab and immunomodulator is recommended. Considering the effect and safety during the 1-year treatment, continuous use for remission maintenance is recommended if the patient responded to the remission induction therapy.

\section{SURGICAL THERAPY}

45. The absolute indications of surgery for UC are uncontrolled bleeding, perforation, and malignancy. Other indications can be severe UC that does not respond to medical treatment, toxic megacolon, uncontrolled symptoms, and cases where continuous medication is impossible because of adverse effects (quality of evidence, moderate; classification of recommendation, strong).

- Level of agreement: strongly agree 65.2\%, agree 34.8\%, uncertain $0 \%$, disagree $0 \%$, strongly disagree $0 \%$

46. The standard surgical methods for UC are total proctocolectomy and ileal pouch-anal anastomosis (IPAA). IPAA can be made by using stapled anastomosis, and mucosectomy is not always necessary (quality of evidence, moderate; classification of recommendation, weak).

- Level of agreement: strongly agree 6.8\%, agree 79.6\%, uncertain $13.6 \%$, disagree $0 \%$, strongly disagree $0 \%$
When making a decision for UC surgery, a compromise must be made among gastroenterologists, colorectal surgeon, and the patient. Common surgical indications in UC are complications such as severe UC unresponsive to treatment, occurrence of dysplasia or malignancy, bleeding, perforation, and toxic megacolon.

Restorative proctocolectomy with IPAA was first introduced in 1978 and is still used as the standard surgery. ${ }^{233}$ Stapled anastomosis is preferred for preservation of anal function during the IPAA. The recommended residual rectal length is within $2 \mathrm{~cm}$. This will lower the rate of future occurrence of inflammation or rectal mucosal malignancy. Mucosectomy and hand-sewn anastomosis show anal dysfunction when compared with stapled anastomosis. ${ }^{234}$ It is not always indicated because of insufficient evidence that it prevents the occurrence of dysplasia or colon cancer. ${ }^{235}$ Temporary loop ileostomy can lower the rates of morbidity and mortality rate by lowering the risk of anastomotic leakage and pelvic sepsis. ${ }^{236}$

Laparoscopic reconstructive proctocolectomy has cosmetic advantages and is associated with lesser pain, faster recovery, and shorter length of hospital stay. Therefore, it is a useful operation method for elective surgery for UC. Operation hours are longer than those in open surgery. However, the complication rate is similar or lower. ${ }^{237}$ In long-term follow-up, laparoscopic surgery lowers the possibility of intraperitoneal adhesion and abdominal hernia, and improves the possibility of pregnancy. ${ }^{238}$

As emergency operation due to bleeding, toxic megacolon, perforation, or fulminant UC, total colectomy and end ileostomy are preferred. These surgical methods preserve the rectum and only remove the colon. When the patient enters a stable state, 1- or 2-staged reconstruction surgery is performed. This operation method can be considered in patients with acute severe UC who have used $\geq 20 \mathrm{mg}$ /day prednisolone continuously for over 6 weeks. Subtotal colectomy, rectosigmoid fistula, or Hartmann's procedure can be the alternative choices. ${ }^{239}$ Laparoscopic operation has many advantages in emergent cases. However, it must be performed by surgeons who have sufficient experience with laparoscopic procedures and UC treatments.

\section{CONCLUSIONS}

UC is a chronic IBD characterized by bloody diarrhea, urgency, and abdominal pain. The incidence and prevalence of UC are constantly increasing during the past decades in Korea, and many patients have been diagnosed with the dis- 
ease. However, the exact pathophysiology of the disease and the treatment methods for cure remain unknown. Although various medical and surgical therapies have been advanced for the management of UC, many challenging issues lead to differences in practice between clinicians. We are hoping that this Korean guidelines will prevent unnecessary or inappropriate, or delayed treatments and lessen the confusion among physicians and researchers. South Korea has insufficient data on UC, but many studies are currently progressing. We hope that more Korean data will be reflected in the next revised version of the Korean guidelines for the management of UC.

\section{ACKNOWLEDGEMENTS}

We thank Dr. Hannah Sun Hae Hwang for her contribution to the editing of manuscript.

\section{REFERENCES}

1. Kornbluth A, Sachar DB; Practice Parameters Committee of the American College of Gastroenterology. Ulcerative colitis practice guidelines in adults: American College Of Gastroenterology, Practice Parameters Committee. Am J Gastroenterol 2010;105:501-523.

2. Su C, Lichtenstein GR. Ulcerative colitis. In: Feldman M, Friedman LS, Brandt LJ, eds. Sleisenger and Fordtran's gastrointestinal and liver disease: pathophysiology, diagnosis, management. Volume 2. 8th ed. Philadelphia: Saunders, 2006:2499-2548.

3. Yang SK, Loftus EV Jr, Sandborn WJ. Epidemiology of inflammatory bowel disease in Asia. Inflamm Bowel Dis 2001;7:260-270.

4. Lakatos PL. Recent trends in the epidemiology of inflammatory bowel diseases: up or down? World J Gastroenterol 2006;12:6102-6108.

5. Ng WK, Wong SH, Ng SC. Changing epidemiological trends of inflammatory bowel disease in Asia. Intest Res 2016;14:111-119.

6. Shivananda S, Lennard-Jones J, Logan R, et al. Incidence of inflammatory bowel disease across Europe: is there a difference between north and south? Results of the European Collaborative Study on Inflammatory Bowel Disease (EC-IBD). Gut 1996;39:690-697.

7. Choi CH, Jung SA, Lee BI, et al. Diagnostic guideline of ulcerative colitis. Korean J Gastroenterol 2009;53:145-160.

8. Kornbluth A, Sachar DB; Practice Parameters Committee of the American College of Gastroenterology. Ulcerative colitis practice guidelines in adults (update): American College of Gastroenterology, Practice Parameters Committee. Am J Gastroenterol 2004;99:1371-1385.
9. Stange EF, Travis SP, Vermeire S, et al. European evidencebased Consensus on the diagnosis and management of ulcerative colitis: definitions and diagnosis. J Crohns Colitis 2008;2:1-23.

10. Choi CH, Kim YH, Kim YS, et al. Guidelines for the management of ulcerative colitis. Intest Res 2012;10:1-25.

11. Travis SP, Stange EF, Lémann M, et al. European evidencebased consensus on the management of ulcerative colitis: current management. J Crohns Colitis 2008;2:24-62.

12. Ueno F, Hibi T. Guidelines for the management treatment of ulcerative colitis in Japan. IBD Res 2010;4:189-239.

13. National Clinical Guideline Centre (UK). Ulcerative colitis: management in adults, children and young people. PubMed Health Web site. http://www.ncbi.nlm.nih.gov/books/ NBK247597/. Accessed January 17, 2017.

14. Bitton A, Buie D, Enns R, et al. Treatment of hospitalized adult patients with severe ulcerative colitis: Toronto consensus statements. Am J Gastroenterol 2012;107:179-194.

15. Bressler B, Marshall JK, Bernstein CN, et al. Clinical practice guidelines for the medical management of nonhospitalized ulcerative colitis: the Toronto consensus. Gastroenterology 2015;148:1035-1058.e3.

16. D'Haens GR, Panaccione R, Higgins PD, et al. The London Position Statement of the World Congress of Gastroenterology on Biological Therapy for IBD with the European Crohn's and Colitis Organization: when to start, when to stop, which drug to choose, and how to predict response? Am J Gastroenterol 2011;106:199-212.

17. Dignass A, Lindsay JO, Sturm A, et al. Second European evidence-based consensus on the diagnosis and management of ulcerative colitis part 2: current management. J Crohns Colitis 2012;6:991-1030.

18. Gomollón F, García-López S, Sicilia B, Gisbert JP, Hinojosa J; Grupo Espa nol de Trabajo en Enfermedad de Crohn y Colitis Ulcerosa. Therapeutic guidelines on ulcerative colitis: a GRADE methodology based effort of GETECCU. Gastroenterol Hepatol 2013;36:104-114.

19. Mowat C, Cole A, Windsor A, et al. Guidelines for the management of inflammatory bowel disease in adults. Gut 2011;60:571-607.

20. Orlando A, Armuzzi A, Papi C, et al. The Italian Society of Gastroenterology (SIGE) and the Italian Group for the study of Inflammatory Bowel Disease (IG-IBD) Clinical Practice Guidelines: the use of tumor necrosis factor-alpha antagonist therapy in inflammatory bowel disease. Dig Liver Dis 2011;43:1-20. 
21. Van Assche G, Lewis JD, Lichtenstein GR, et al. The London position statement of the World Congress of Gastroenterology on Biological Therapy for IBD with the European Crohn's and Colitis Organisation: safety. Am J Gastroenterol 2011;106:15941602.

22. Balshem H, Helfand M, Schünemann HJ, et al. GRADE guidelines: 3. rating the quality of evidence. J Clin Epidemiol 2011;64:401-406.

23. Guyatt GH, Oxman AD, Vist GE, et al. GRADE: an emerging consensus on rating quality of evidence and strength of recommendations. BMJ 2008;336:924-926.

24. Lee KM, Kim YS, Seo GS, Kim TO, Yang SK; IBD Study Group of the Korean Association for the Study of Intestinal Diseases. Use of thiopurines in inflammatory bowel disease: a consensus statement by the Korean Association for the Study of Intestinal Diseases (KASID). Intest Res 2015;13:193-207.

25. Guyatt GH, Oxman AD, Kunz R, et al. Going from evidence to recommendations. BMJ 2008;336:1049-1051.

26. Su C, Lewis JD, Goldberg B, Brensinger C, Lichtenstein GR. A meta-analysis of the placebo rates of remission and response in clinical trials of active ulcerative colitis. Gastroenterology 2007;132:516-526.

27. Truelove SC, Witts LJ. Cortisone in ulcerative colitis: final report on a therapeutic trial. Br Med J 1955;2:1041-1048.

28. Levi AJ, Fisher AM, Hughes L, Hendry WF. Male infertility due to sulphasalazine. Lancet 1979;2:276-278.

29. Toovey S, Hudson E, Hendry WF, Levi AJ. Sulphasalazine and male infertility: reversibility and possible mechanism. Gut 1981;22:445-451.

30. Toth A. Male infertility due to sulphasalazine. Lancet 1979;2:904

31. Gisbert JP, González-Lama Y, Maté J. 5-Aminosalicylates and renal function in inflammatory bowel disease: a systematic review. Inflamm Bowel Dis 2007;13:629-638.

32. Bergman R, Parkes M. Systematic review: the use of mesalazine in inflammatory bowel disease. Aliment Pharmacol Ther 2006;23:841-855.

33. Cohen RD, Woseth DM, Thisted RA, Hanauer SB. A metaanalysis and overview of the literature on treatment options for left-sided ulcerative colitis and ulcerative proctitis. Am J Gastroenterol 2000;95:1263-1276.

34. Ford AC, Khan KJ, Achkar JP, Moayyedi P. Efficacy of oral vs. topical, or combined oral and topical 5-aminosalicylates, in ulcerative colitis: systematic review and meta-analysis. Am J Gastroenterol 2012;107:167-176.
35. Manguso F, Balzano A. Meta-analysis: the efficacy of rectal beclomethasone dipropionate vs. 5-aminosalicylic acid in mild to moderate distal ulcerative colitis. Aliment Pharmacol Ther 2007;26:21-29.

36. Marshall JK, Irvine EJ. Putting rectal 5-aminosalicylic acid in its place: the role in distal ulcerative colitis. Am J Gastroenterol 2000;95:1628-1636.

37. Marshall JK, Thabane M, Steinhart AH, Newman JR, Anand A, Irvine EJ. Rectal 5-aminosalicylic acid for induction of remission in ulcerative colitis. Cochrane Database Syst Rev 2010;(1):CD004115. doi: 10.1002/14651858.CD004115.pub2.

38. Marshall JK, Irvine EJ. Rectal aminosalicylate therapy for distal ulcerative colitis: a meta-analysis. Aliment Pharmacol Ther 1995;9:293-300.

39. Watanabe M, Nishino H, Sameshima Y, Ota A, Nakamura S, Hibi T. Randomised clinical trial: evaluation of the efficacy of mesalazine (mesalamine) suppositories in patients with ulcerative colitis and active rectal inflammation: a placebocontrolled study. Aliment Pharmacol Ther 2013;38:264-273.

40. van Bodegraven AA, Boer RO, Lourens J, Tuynman HA, Sindram JW. Distribution of mesalazine enemas in active and quiescent ulcerative colitis. Aliment Pharmacol Ther 1996;10:327-332.

41. Gionchetti P, Rizzello F, Venturi A, et al. Comparison of mesalazine suppositories in proctitis and distal proctosigmoiditis. Aliment Pharmacol Ther 1997;11:1053-1057.

42. Andus T, Kocjan A, Müser M, et al. Clinical trial: a novel highdose $1 \mathrm{~g}$ mesalamine suppository (Salofalk) once daily is as efficacious as a 500-mg suppository thrice daily in active ulcerative proctitis. Inflamm Bowel Dis 2010;16:1947-1956.

43. Lamet M. A multicenter, randomized study to evaluate the efficacy and safety of mesalamine suppositories $1 \mathrm{~g}$ at bedtime and $500 \mathrm{mg}$ Twice daily in patients with active mild-to-moderate ulcerative proctitis. Dig Dis Sci 201 1;56:513-522.

44. Marshall JK, Irvine EJ. Rectal corticosteroids versus alternative treatments in ulcerative colitis: a meta-analysis. Gut 1997;40:775-781.

45. Hartmann F, Stein J; BudMesa-Study Group. Clinical trial: controlled, open, randomized multicentre study comparing the effects of treatment on quality of life, safety and efficacy of budesonide or mesalazine enemas in active left-sided ulcerative colitis. Aliment Pharmacol Ther 2010;32:368-376.

46. Lémann M, Galian A, Rutgeerts P, et al. Comparison of budesonide and 5-aminosalicylic acid enemas in active distal ulcerative colitis. Aliment Pharmacol Ther 1995;9:557-562.

47. Regueiro M, Loftus EV Jr, Steinhart AH, Cohen RD. Medical management of left-sided ulcerative colitis and ulcerative proctitis: critical evaluation of therapeutic trials. Inflamm Bowel Dis 2006;12:979-994. 
48. Gionchetti P, Rizzello F, Venturi A, et al. Comparison of oral with rectal mesalazine in the treatment of ulcerative proctitis. Dis Colon Rectum 1998;41:93-97.

49. Ito H, Iida M, Matsumoto T, et al. Direct comparison of two different mesalamine formulations for the induction of remission in patients with ulcerative colitis: a double-blind, randomized study. Inflamm Bowel Dis 2010;16:1567-1574.

50. Safdi M, DeMicco M, Sninsky C, et al. A double-blind comparison of oral versus rectal mesalamine versus combination therapy in the treatment of distal ulcerative colitis. Am J Gastroenterol 1997;92:1867-1871.

51. Mulder CJ, Fockens P, Meijer JW, van der Heide H, Wiltink EH, Tytgat GN. Beclomethasone dipropionate (3 mg) versus 5 -aminosalicylic acid ( $2 \mathrm{~g}$ ) versus the combination of both (3 $\mathrm{mg} / 2 \mathrm{~g}$ ) as retention enemas in active ulcerative proctitis. Eur J Gastroenterol Hepatol 1996;8:549-553.

52. Levine DS, Riff DS, Pruitt R, et al. A randomized, double blind, dose-response comparison of balsalazide (6.75 g), balsalazide (2.25 g), and mesalamine (2.4 g) in the treatment of active, mild-to-moderate ulcerative colitis. Am J Gastroenterol 2002;97:1398-1407.

53. Pruitt R, Hanson J, Safdi M, et al. Balsalazide is superior to mesalamine in the time to improvement of signs and symptoms of acute mild-to-moderate ulcerative colitis. Am J Gastroenterol 2002;97:3078-3086.

54. Cortot A, Maetz D, Degoutte E, et al. Mesalamine foam enema versus mesalamine liquid enema in active left-sided ulcerative colitis. Am J Gastroenterol 2008;103:3106-3114.

55. Farup PG, Hovde O, Halvorsen FA, Raknerud N, Brodin U. Mesalazine suppositories versus hydrocortisone foam in patients with distal ulcerative colitis: a comparison of the efficacy and practicality of two topical treatment regimens. Scand J Gastroenterol 1995;30:164-170.

56. Kamm MA, Lichtenstein GR, Sandborn WJ, et al. Effect of extended MMX mesalamine therapy for acute, mild-to-moderate ulcerative colitis. Inflamm Bowel Dis 2009;15:1-8.

57. Kane SV, Bjorkman DJ. The efficacy of oral 5-ASAs in the treatment of active ulcerative colitis: a systematic review. Rev Gastroenterol Disord 2003;3:210-218.

58. Feagan BG, Macdonald JK. Oral 5-aminosalicylic acid for induction of remission in ulcerative colitis. Cochrane Database Syst Rev 2012;10:CD000543. doi: 10.1002/14651858. CD000543.pub3.

59. Ford AC, Achkar JP, Khan KJ, et al. Efficacy of 5-aminosalicylates in ulcerative colitis: systematic review and meta-analysis. Am J Gastroenterol 2011;106:601-616.
60. Sutherland L, Macdonald JK. Oral 5-aminosalicylic acid for induction of remission in ulcerative colitis. Cochrane Database Syst Rev 2006;(2):CD000543. doi: 10.1002/14651858. CD000543.pub2.

61. Bebb JR, Scott BB. How effective are the usual treatments for ulcerative colitis? Aliment Pharmacol Ther 2004;20:143-149.

62. Hanauer SB, Sandborn WJ, Kornbluth A, et al. Delayed-release oral mesalamine at $4.8 \mathrm{~g} / \mathrm{day}$ (800 $\mathrm{mg}$ tablet) for the treatment of moderately active ulcerative colitis: the ASCEND II trial. Am J Gastroenterol 2005;100:2478-2485.

63. Pimpo MT, Galletti B, Palumbo G, et al. Mesalazine vanishing time from rectal mucosa following its topical administration. J Crohns Colitis 2010;4:102-105.

64. Marteau P, Probert CS, Lindgren S, et al. Combined oral and enema treatment with Pentasa (mesalazine) is superior to oral therapy alone in patients with extensive mild/moderate active ulcerative colitis: a randomised, double blind, placebo controlled study. Gut 2005;54:960-965.

65. Feagan BG, Chande N, MacDonald JK. Are there any differences in the efficacy and safety of different formulations of oral 5-ASA used for induction and maintenance of remission in ulcerative colitis? Evidence from cochrane reviews. Inflamm Bowel Dis 2013;19:2031-2040.

66. Feagan BG, MacDonald JK. Once daily oral mesalamine compared to conventional dosing for induction and maintenance of remission in ulcerative colitis: a systematic review and meta-analysis. Inflamm Bowel Dis 2012;18:1785-1794.

67. Kruis W, Kiudelis G, Rácz I, et al. Once daily versus three times daily mesalazine granules in active ulcerative colitis: a doubleblind, double-dummy, randomised, non-inferiority trial. Gut 2009;58:233-240.

68. Sandborn WJ, Korzenik J, Lashner B, et al. Once-daily dosing of delayed-release oral mesalamine (400-mg tablet) is as effective as twice-daily dosing for maintenance of remission of ulcerative colitis. Gastroenterology 2010;138:1286-1296.e3.

69. Lichtenstein GR, Kamm MA, Boddu P, et al. Effect of once- or twice-daily MMX mesalamine (SPD476) for the induction of remission of mild to moderately active ulcerative colitis. Clin Gastroenterol Hepatol 2007;5:95-102.

70. Kamm MA, Sandborn WJ, Gassull M, et al. Once-daily, highconcentration MMX mesalamine in active ulcerative colitis. Gastroenterology 2007;132:66-75.

71. Turner D, Walsh CM, Steinhart AH, Griffiths AM. Response to corticosteroids in severe ulcerative colitis: a systematic review of the literature and a meta-regression. Clin Gastroenterol Hepatol 2007;5:103-110.

72. Stein RB, Hanauer SB. Medical therapy for inflammatory bowel disease. Gastroenterol Clin North Am 1999;28:297-321. 
73. Meyers S. Oral and parenteral corticoids. In: Peppercorn MA, ed. Therapy of inflammatory bowel disease: new medical and surgical approaches. New York: Marcel Decker, 1990:1-34.

74. Baron JH, Connell AM, Kanaghinis TG, Lennard-Jones JE, Jones AF. Out-patient treatment of ulcerative colitis. Comparison between three doses of oral prednisone. Br Med J 1962;2:441-443.

75. Campieri M, Adamo S, Valpiani D, et al. Oral beclometasone dipropionate in the treatment of extensive and left-sided active ulcerative colitis: a multicentre randomised study. Aliment Pharmacol Ther 2003;17:1471-1480.

76. Papi C, Aratari A, Moretti A, et al. Oral beclomethasone dipropionate as an alternative to systemic steroids in mild to moderate ulcerative colitis not responding to aminosalicylates. Dig Dis Sci 2010;55:2002-2007.

77. Zhao X, Li N, Ren Y, et al. Efficacy and safety of beclomethasone dipropionate versus 5-aminosalicylic acid in the treatment of ulcerative colitis: a systematic review and metaanalysis. PLoS One 2016;11:e0160500. doi: 10.1371/journal. pone.0160500.

78. Sandborn WJ, Travis S, Moro L, et al. Once-daily budesonide $\mathrm{MMX}^{\circledR}$ extended-release tablets induce remission in patients with mild to moderate ulcerative colitis: results from the CORE I study. Gastroenterology 2012;143:1218-1226.e2.

79. Travis SP, Danese S, Kupcinskas L, et al. Once-daily budesonide MMX in active, mild-to-moderate ulcerative colitis: results from the randomised CORE II study. Gut 2014;63:433-441.

80. Ardizzone S, Maconi G, Russo A, Imbesi V, Colombo E, Bianchi Porro G. Randomised controlled trial of azathioprine and 5 -aminosalicylic acid for treatment of steroid dependent ulcerative colitis. Gut 2006;55:47-53.

81. Burger D, Travis S. Conventional medical management of inflammatory bowel disease. Gastroenterology 2011;140:18271837.e2.

82. Terdiman JP, Gruss CB, Heidelbaugh JJ, Sultan S, Falck-Ytter YT; AGA Institute Clinical Practice and Quality Management Committee. American Gastroenterological Association Institute guideline on the use of thiopurines, methotrexate, and anti-TNF-alpha biologic drugs for the induction and maintenance of remission in inflammatory Crohn's disease. Gastroenterology 2013;145:1459-1463.

83. D’Haens G, Geboes K, Rutgeerts P. Endoscopic and histologic healing of Crohn's (ileo-) colitis with azathioprine. Gastrointest Endosc 1999;50:667-671.

84. Adler DJ, Korelitz BI. The therapeutic efficacy of 6-mercaptopurine in refractory ulcerative colitis. Am J Gastroenterol 1990;85:717-722.
85. Chebli LA, Chaves LD, Pimentel FF, et al. Azathioprine maintains long-term steroid-free remission through 3 years in patients with steroid-dependent ulcerative colitis. Inflamm Bowel Dis 2010;16:613-619.

86. Gisbert JP, Niño P, Cara C, Rodrigo L. Comparative effectiveness of azathioprine in Crohn's disease and ulcerative colitis: prospective, long-term, follow-up study of 394 patients. Aliment Pharmacol Ther 2008;28:228-238.

87. Holtmann MH, Krummenauer F, Claas C, et al. Long-term effectiveness of azathioprine in IBD beyond 4 years: a European multicenter study in 1176 patients. Dig Dis Sci 2006;51:1516-1524.

88. Kirk AP, Lennard-Jones JE. Controlled trial of azathioprine in chronic ulcerative colitis. Br Med J (Clin Res Ed) 1982;284:1291-1292.

89. Rosenberg JL, Wall AJ, Levin B, Binder HJ, Kirsner JB. A controlled trial of azathioprine in the management of chronic ulcerative colitis. Gastroenterology 1975;69:96-99.

90. Rutgeerts P, Sandborn WJ, Feagan BG, et al. Infliximab for induction and maintenance therapy for ulcerative colitis. N Engl J Med 2005;353:2462-2476.

91. Colombel JF, Rutgeerts P, Reinisch W, et al. Early mucosal healing with infliximab is associated with improved longterm clinical outcomes in ulcerative colitis. Gastroenterology 2011;141:1194-1201.

92. Reinisch W, Sandborn WJ, Hommes DW, et al. Adalimumab for induction of clinical remission in moderately to severely active ulcerative colitis: results of a randomised controlled trial. Gut 2011;60:780-787.

93. Sandborn WJ, van Assche G, Reinisch W, et al. Adalimumab induces and maintains clinical remission in patients with moderate-to-severe ulcerative colitis. Gastroenterology 2012;142:257-265.e3.

94. Sandborn WJ, Feagan BG, Marano C, et al. Subcutaneous golimumab induces clinical response and remission in patients with moderate-to-severe ulcerative colitis. Gastroenterology 2014;146:85-95.

95. Panaccione R, Ghosh S, Middleton S, et al. Combination therapy with infliximab and azathioprine is superior to monotherapy with either agent in ulcerative colitis. Gastroenterology 2014;146:392-400.e3.

96. Ford AC, Bernstein CN, Khan KJ, et al. Glucocorticosteroid therapy in inflammatory bowel disease: systematic review and meta-analysis. Am J Gastroenterol 2011;106:590-599.

97. Dignass A, Van Assche G, Lindsay JO, et al. The second European evidence-based consensus on the diagnosis and management of Crohn's disease: current management. J Crohns Colitis 2010;4:28-62. 
98. Lichtenstein GR, Abreu MT, Cohen R, Tremaine W; American Gastroenterological Association. American Gastroenterological Association Institute technical review on corticosteroids, immunomodulators, and infliximab in inflammatory bowel disease. Gastroenterology 2006;130:940-987.

99. Sonnenberg A. Time trends of mortality from Crohn's disease and ulcerative colitis. Int J Epidemiol 2007;36:890-899.

100. Bossa F, Fiorella S, Caruso N, et al. Continuous infusion versus bolus administration of steroids in severe attacks of ulcerative colitis: a randomized, double-blind trial. Am J Gastroenterol 2007;102:601-608

101. Domènech E, Vega R, Ojanguren I, et al. Cytomegalovirus infection in ulcerative colitis: a prospective, comparative study on prevalence and diagnostic strategy. Inflamm Bowel Dis 2008;14:1373-1379.

102. Gan SI, Beck PL. A new look at toxic megacolon: an update and review of incidence, etiology, pathogenesis, and management. Am J Gastroenterol 2003;98:2363-2371.

103. Criscuoli V, Casà A, Orlando A, et al. Severe acute colitis associated with CMV: a prevalence study. Dig Liver Dis 2004;36:818820.

104. Cottone M, Pietrosi G, Martorana G, et al. Prevalence of cytomegalovirus infection in severe refractory ulcerative and Crohn's colitis. Am J Gastroenterol 2001;96:773-775.

105. Randall J, Singh B, Warren BF, Travis SP, Mortensen NJ, George BD. Delayed surgery for acute severe colitis is associated with increased risk of postoperative complications. Br J Surg 2010;97:404-409.

106. Travis SP, Farrant JM, Ricketts C, et al. Predicting outcome in severe ulcerative colitis. Gut 1996;38:905-910.

107. Seo M, Okada M, Yao T, Matake H, Maeda K. Evaluation of the clinical course of acute attacks in patients with ulcerative colitis through the use of an activity index. J Gastroenterol 2002;37:29-34.

108. Ho GT, Mowat C, Goddard CJ, et al. Predicting the outcome of severe ulcerative colitis: development of a novel risk score to aid early selection of patients for second-line medical therapy or surgery. Aliment Pharmacol Ther 2004;19:1079-1087.

109. Travis SP. Predicting outcome in severe ulcerative colitis. Dig Liver Dis 2004;36:448-449.

110. Daperno M, Sostegni R, Scaglione N, et al. Outcome of a conservative approach in severe ulcerative colitis. Dig Liver Dis 2004;36:21-28.

111. Carbonnel F, Gargouri D, Lémann M, et al. Predictive factors of outcome of intensive intravenous treatment for attacks of ulcerative colitis. Aliment Pharmacol Ther 2000;14:273-279.

112. Chew CN, Nolan DJ, Jewell DP. Small bowel gas in severe ulcerative colitis. Gut 1991;32:1535-1537.
113. Lennard-Jones JE, Ritchie JK, Hilder W, Spicer CC. Assessment of severity in colitis: a preliminary study. Gut 1975;16:579-584.

114. McIntyre PB, Powell-Tuck J, Wood SR, et al. Controlled trial of bowel rest in the treatment of severe acute colitis. Gut 1986;27:481-485.

115. González-Huix F, Fernández-Bañares F, Esteve-Comas M, et al. Enteral versus parenteral nutrition as adjunct therapy in acute ulcerative colitis. Am J Gastroenterol 1993;88:227-232.

116. Dickinson RJ, Ashton MG, Axon AT, Smith RC, Yeung CK, Hill GL. Controlled trial of intravenous hyperalimentation and total bowel rest as an adjunct to the routine therapy of acute colitis. Gastroenterology 1980;79:1199-1204.

117. Chapman RW, Selby WS, Jewell DP. Controlled trial of intravenous metronidazole as an adjunct to corticosteroids in severe ulcerative colitis. Gut 1986;27:1210-1212.

118. Mantzaris GJ, Hatzis A, Kontogiannis P, Triadaphyllou G. Intravenous tobramycin and metronidazole as an adjunct to corticosteroids in acute, severe ulcerative colitis. Am J Gastroenterol 1994;89:43-46.

119. Mantzaris GJ, Petraki K, Archavlis E, et al. A prospective randomized controlled trial of intravenous ciprofloxacin as an adjunct to corticosteroids in acute, severe ulcerative colitis. Scand J Gastroenterol 2001;36:971-974.

120. Ford AC, Sandborn WJ, Khan KJ, Hanauer SB, Talley NJ, Moayyedi P. Efficacy of biological therapies in inflammatory bowel disease: systematic review and meta-analysis. Am J Gastroenterol 2011;106:644-659.

121. Lawson MM, Thomas AG, Akobeng AK. Tumour necrosis factor alpha blocking agents for induction of remission in ulcerative colitis. Cochrane Database Syst Rev 2006;(3):CD005112. doi: 10.1002/14651858.CD005112.pub2.

122. Lv R, Qiao W, Wu Z, et al. Tumor necrosis factor alpha blocking agents as treatment for ulcerative colitis intolerant or refractory to conventional medical therapy: a meta-analysis. PLoS One 2014;9:e86692. doi: 10.1371/journal.pone.0086692.

123. Järnerot G, Hertervig E, Friis-Liby I, et al. Infliximab as rescue therapy in severe to moderately severe ulcerative colitis: a randomized, placebo-controlled study. Gastroenterology 2005;128:1805-1811.

124. Ford AC, Peyrin-Biroulet L. Opportunistic infections with antitumor necrosis factor-alpha therapy in inflammatory bowel disease: meta-analysis of randomized controlled trials. Am J Gastroenterol 2013;108:1268-1276.

125. Targownik LE, Bernstein CN. Infectious and malignant complications of TNF inhibitor therapy in IBD. Am J Gastroenterol 2013;108:1835-1842. 
126. Kishore J, Ghoshal U, Ghoshal UC, et al. Infection with cytomegalovirus in patients with inflammatory bowel disease: prevalence, clinical significance and outcome. J Med Microbiol 2004;53(Pt 11):1155-1160.

127. Papadakis KA, Tung JK, Binder SW, et al. Outcome of cytomegalovirus infections in patients with inflammatory bowel disease. Am J Gastroenterol 2001;96:2137-2142.

128. Kim YS, Kim YH, Kim JS, et al. The prevalence and efficacy of ganciclovir on steroid-refractory ulcerative colitis with cytomegalovirus infection: a prospective multicenter study. J Clin Gastroenterol 2012;46:51-56.

129. Kim YS, Kim YH, Kim JS, et al. Long-term outcomes of cytomegalovirus reactivation in patients with moderate to severe ulcerative colitis: a multicenter study. Gut Liver 2014;8:643647.

130. Lichtiger S, Present DH, Kornbluth A, et al. Cyclosporine in severe ulcerative colitis refractory to steroid therapy. N Engl J Med 1994;330:1841-1845.

131. Van Assche G, D'Haens G, Noman M, et al. Randomized, double-blind comparison of $4 \mathrm{mg} / \mathrm{kg}$ versus $2 \mathrm{mg} / \mathrm{kg}$ intravenous cyclosporine in severe ulcerative colitis. Gastroenterology 2003;125:1025-1031.

132. D’Haens G, Lemmens L, Geboes K, et al. Intravenous cyclosporine versus intravenous corticosteroids as single therapy for severe attacks of ulcerative colitis. Gastroenterology 2001;120:1323-1329.

133. Cohen RD, Stein R, Hanauer SB. Intravenous cyclosporin in ulcerative colitis: a five-year experience. Am J Gastroenterol 1999;94:1587-1592.

134. Moskovitz DN, Van Assche G, Maenhout B, et al. Incidence of colectomy during long-term follow-up after cyclosporine-induced remission of severe ulcerative colitis. Clin Gastroenterol Hepatol 2006;4:760-765.

135. Shibolet O, Regushevskaya E, Brezis M, Soares-Weiser K. Cyclosporine A for induction of remission in severe ulcerative colitis. Cochrane Database Syst Rev 2005;(1):CD004277. doi: 10.1002/14651858.CD004277.pub2.

136. Campbell S, Travis S, Jewell D. Ciclosporin use in acute ulcerative colitis: a long-term experience. Eur J Gastroenterol Hepatol 2005; 17:79-84.

137. Cheifetz AS, Stern J, Garud S, et al. Cyclosporine is safe and effective in patients with severe ulcerative colitis. J Clin Gastroenterol 2011;45:107-112.

138. Bamba S, Tsujikawa T, Inatomi O, et al. Factors affecting the efficacy of cyclosporin A therapy for refractory ulcerative colitis. J Gastroenterol Hepatol 2010;25:494-498.
139. Walch A, Meshkat M, Vogelsang H, et al. Long-term outcome in patients with ulcerative colitis treated with intravenous cyclosporine $\mathrm{A}$ is determined by previous exposure to thiopurines. J Crohns Colitis 2010;4:398-404.

140. Giaffer MH, Holdsworth CD, Lennard-Jones JE, et al. Improved maintenance of remission in ulcerative colitis by balsalazide 4 g/day compared with 2 g/day. Aliment Pharmacol Ther 1992;6:479-485.

141. Ananthakrishnan AN, McGinley EL. Infection-related hospitalizations are associated with increased mortality in patients with inflammatory bowel diseases. J Crohns Colitis 2013;7:107-112.

142. Kaplan GG, McCarthy EP, Ayanian JZ, Korzenik J, Hodin R, Sands BE. Impact of hospital volume on postoperative morbidity and mortality following a colectomy for ulcerative colitis. Gastroenterology 2008;134:680-687.

143. Westhovens R, Yocum D, Han J, et al. The safety of infliximab, combined with background treatments, among patients with rheumatoid arthritis and various comorbidities: a large, randomized, placebo-controlled trial. Arthritis Rheum 2006;54:1075-1086.

144. Bongartz T, Sutton AJ, Sweeting MJ, Buchan I, Matteson EL, Montori V. Anti-TNF antibody therapy in rheumatoid arthritis and the risk of serious infections and malignancies: systematic review and meta-analysis of rare harmful effects in randomized controlled trials. JAMA 2006;295:2275-2285.

145. Rahier JF, Magro F, Abreu C, et al. Second European evidencebased consensus on the prevention, diagnosis and management of opportunistic infections in inflammatory bowel disease. J Crohns Colitis 2014;8:443-468.

146. Harigai M, Koike R, Miyasaka N; Pneumocystis Pneumonia under Anti-Tumor Necrosis Factor Therapy (PAT) Study Group. Pneumocystis pneumonia associated with infliximab in Japan. N Engl J Med 2007;357:1874-1876.

147. Keane J, Gershon S, Wise RP, et al. Tuberculosis associated with infliximab, a tumor necrosis factor alpha-neutralizing agent. N Engl J Med 2001;345:1098-1104.

148. Targeted tuberculin testing and treatment of latent tuberculosis infection. This official statement of the American Thoracic Society was adopted by the ATS Board of Directors, July 1999 This is a Joint Statement of the American Thoracic Society (ATS) and the Centers for Disease Control and Prevention (CDC). This statement was endorsed by the Council of the Infectious Diseases Society of America. (IDSA), September 1999, and the sections of this statement. Am J Respir Crit Care Med 2000;161(4 Pt 2):S221-S247. 
149. Shim TS. Diagnosis and treatment of latent tuberculosis infection in patients with inflammatory bowel diseases due to initiation of anti-tumor necrosis factor therapy. Intest Res 2014;12:12-19.

150. Loras C, Gisbert JP, Mínguez M, et al. Liver dysfunction related to hepatitis $\mathrm{B}$ and $\mathrm{C}$ in patients with inflammatory bowel disease treated with immunosuppressive therapy. Gut 2010;59:1340-1346.

151. Park SH, Yang SK, Lim YS, et al. Clinical courses of chronic hepatitis B virus infection and inflammatory bowel disease in patients with both diseases. Inflamm Bowel Dis 2012;18:2004-2010.

152. Gisbert JP, Villagrasa JR, Rodríguez-Nogueiras A, Chaparro M. Efficacy of hepatitis B vaccination and revaccination and factors impacting on response in patients with inflammatory bowel disease. Am J Gastroenterol 2012;107:1460-1466.

153. Green JR, Swan CH, Rowlinson A, et al. Short report: comparison of two doses of balsalazide in maintaining ulcerative colitis in remission over 12 months. Aliment Pharmacol Ther 1992;6:647-652.

154. Osterman MT, Sandborn WJ, Colombel JF, et al. Increased risk of malignancy with adalimumab combination therapy, compared with monotherapy, for Crohn's disease. Gastroenterology 2014;146:941-949.

155. An oral preparation of mesalamine as long-term maintenance therapy for ulcerative colitis: a randomized, placebo-controlled trial. The Mesalamine Study Group. Ann Intern Med 1996;124:204-211.

156. Adedokun OJ, Sandborn WJ, Feagan BG, et al. Association between serum concentration of infliximab and efficacy in adult patients with ulcerative colitis. Gastroenterology 2014;147:1296-1307.e5.

157. Roblin X, Marotte H, Rinaudo M, et al. Association between pharmacokinetics of adalimumab and mucosal healing in patients with inflammatory bowel diseases. Clin Gastroenterol Hepatol 2014;12:80-84.e2.

158. Hibi T, Sakuraba A, Watanabe M, et al. Retrieval of serum infliximab level by shortening the maintenance infusion interval is correlated with clinical efficacy in Crohn's disease. Inflamm Bowel Dis 2012;18:1480-1487.

159. Afif W, Loftus EV Jr, Faubion WA, et al. Clinical utility of measuring infliximab and human anti-chimeric antibody concentrations in patients with inflammatory bowel disease. Am J Gastroenterol 2010;105:1133-1139.

160. Roblin X, Rinaudo M, Del Tedesco E, et al. Development of an algorithm incorporating pharmacokinetics of adalimumab in inflammatory bowel diseases. Am J Gastroenterol 2014;109:1250-1256.
161. Papamichael K, Rivals-Lerebours O, Billiet T, et al. Long-term outcome of patients with ulcerative colitis and primary nonresponse to infliximab. J Crohns Colitis 2016;10:1015-1023.

162. Feagan BG, Rutgeerts P, Sands BE, et al. Vedolizumab as induction and maintenance therapy for ulcerative colitis. N Engl J Med 2013;369:699-710.

163. Parikh A, Leach T, Wyant T, et al. Vedolizumab for the treatment of active ulcerative colitis: a randomized controlled phase 2 dose-ranging study. Inflamm Bowel Dis 2012;18:1470-1479.

164. Kotlyar DS, Osterman MT, Diamond RH, et al. A systematic review of factors that contribute to hepatosplenic T-cell lymphoma in patients with inflammatory bowel disease. Clin Gastroenterol Hepatol 2011;9:36-41.e1.

165. Pouw MF, Krieckaert CL, Nurmohamed MT, et al. Key findings towards optimising adalimumab treatment: the concentration-effect curve. Ann Rheum Dis 2015;74:513-518.

166. El-Matary W, Vandermeer B, Griffiths AM. Methotrexate for maintenance of remission in ulcerative colitis. Cochrane Database Syst Rev 2009;(3):CD007560. doi: 10.1002/14651858. CD007560.pub2.

167. Shen J, Zuo ZX, Mao AP. Effect of probiotics on inducing remission and maintaining therapy in ulcerative colitis, Crohn's disease, and pouchitis: meta-analysis of randomized controlled trials. Inflamm Bowel Dis 2014;20:21-35.

168. Mardini HE, Grigorian AY. Probiotic mix VSL\#3 is effective adjunctive therapy for mild to moderately active ulcerative colitis: a meta-analysis. Inflamm Bowel Dis 2014;20:1562-1567.

169. Losurdo G, Iannone A, Contaldo A, Ierardi E, Di Leo A, Principi M. Escherichia coli nissle 1917 in ulcerative colitis treatment: systematic review and meta-analysis. J Gastrointestin Liver Dis 2015;24:499-505.

170. Petersen AM, Mirsepasi H, Halkjær SI, Mortensen EM, Nordgaard-Lassen I, Krogfelt KA. Ciprofloxacin and probiotic Escherichia coli Nissle add-on treatment in active ulcerative colitis: a double-blind randomized placebo controlled clinical trial. J Crohns Colitis 2014;8:1498-1505.

171. Higgins PD, Rubin DT, Kaulback K, Schoenfield PS, Kane SV. Systematic review: impact of non-adherence to 5-aminosalicylic acid products on the frequency and cost of ulcerative colitis flares. Aliment Pharmacol Ther 2009;29:247-257.

172. Kane S, Huo D, Aikens J, Hanauer S. Medication nonadherence and the outcomes of patients with quiescent ulcerative colitis. Am J Med 2003;114:39-43.

173. Sutherland L, Macdonald JK. Oral 5-aminosalicylic acid for maintenance of remission in ulcerative colitis. Cochrane Database Syst Rev 2006;(2):CD000544. doi. 10.1002/14651858. CD000544.pub2. 
174. Lichtenstein GR, Ramsey D, Rubin DT. Randomised clinical trial: delayed-release oral mesalazine $4.8 \mathrm{~g} /$ day vs. $2.4 \mathrm{~g} /$ day in endoscopic mucosal healing. ASCEND I and II combined analysis. Aliment Pharmacol Ther 2011;33:672-678.

175. Kamm MA, Lichtenstein GR, Sandborn WJ, et al. Randomised trial of once- or twice-daily MMX mesalazine for maintenance of remission in ulcerative colitis. Gut 2008;57:893-902.

176. Sandberg-Gertzén H, Järnerot G, Kraaz W. Azodisal sodium in the treatment of ulcerative colitis: a study of tolerance and relapseprevention properties. Gastroenterology 1986;90:1024-1030.

177. Miner P, Hanauer S, Robinson M, Schwartz J, Arora S. Safety and efficacy of controlled-release mesalamine for maintenance of remission in ulcerative colitis: Pentasa UC Maintenance Study Group. Dig Dis Sci 1995;40:296-304.

178. Hawkey CJ, Dube LM, Rountree LV, Linnen PJ, Lancaster JF. A trial of zileuton versus mesalazine or placebo in the maintenance of remission of ulcerative colitis: the European Zileuton Study Group for Ulcerative Colitis. Gastroenterology 1997;112:718-724.

179. Kruis W, Jonaitis L, Pokrotnieks J, et al. Randomised clinical trial: a comparative dose-finding study of three arms of dual release mesalazine for maintaining remission in ulcerative colitis. Aliment Pharmacol Ther 2011;33:313-322.

180. Ford AC, Khan KJ, Sandborn WJ, Hanauer SB, Moayyedi P. Efficacy of topical 5-aminosalicylates in preventing relapse of quiescent ulcerative colitis: a meta-analysis. Clin Gastroenterol Hepatol 2012;10:513-519.

181. Marshall JK, Thabane M, Steinhart AH, Newman JR, Anand A, Irvine EJ. Rectal 5-aminosalicylic acid for maintenance of remission in ulcerative colitis. Cochrane Database Syst Rev 2012;11:CD004118. doi: 10.1002/14651858.CD004118.pub2.

182. d'Albasio G, Pacini F, Camarri E, et al. Combined therapy with 5-aminosalicylic acid tablets and enemas for maintaining remission in ulcerative colitis: a randomized double-blind study. Am J Gastroenterol 1997;92:1143-1147.

183. Fockens P, Mulder CJ, Tytgat GN, et al. Comparison of the efficacy and safety of 1.5 compared with $3.0 \mathrm{~g}$ oral slow-release mesalazine (Pentasa) in the maintenance treatment of ulcerative colitis. Dutch Pentasa Study Group Eur J Gastroenterol Hepatol 1995;7:1025-1030.

184. Feagan BG, Macdonald JK. Oral 5-aminosalicylic acid for maintenance of remission in ulcerative colitis. Cochrane Database Syst Rev 2012;10:CD000544. doi: 10.1002/14651858. CD000544.pub3.

185. Truelove SC, Jewell DP. Intensive intravenous regimen for severe attacks of ulcerative colitis. Lancet 1974;1:1067-1070.
186. Paoluzi OA, Iacopini F, Pica R, et al. Comparison of two different daily dosages (2.4 vs. $1.2 \mathrm{~g}$ ) of oral mesalazine in maintenance of remission in ulcerative colitis patients: 1-year followup study. Aliment Pharmacol Ther 2005;21:1111-1119.

187. Rodemann JF, Dubberke ER, Reske KA, Seo DH, Stone CD. Incidence of Clostridium difficile infection in inflammatory bowel disease. Clin Gastroenterol Hepatol 2007;5:339-344.

188. Azad Khan AK, Howes DT, Piris J, Truelove SC. Optimum dose of sulphasalazine for maintenance treatment in ulcerative colitis. Gut 1980;21:232-240.

189. Dignass AU, Bokemeyer B, Adamek H, et al. Mesalamine once daily is more effective than twice daily in patients with quiescent ulcerative colitis. Clin Gastroenterol Hepatol 2009;7:762-769.

190. Gisbert JP, Linares PM, McNicholl AG, Maté J, Gomollón F. Meta-analysis: the efficacy of azathioprine and mercaptopurine in ulcerative colitis. Aliment Pharmacol Ther 2009;30:126-137.

191. Khan KJ, Dubinsky MC, Ford AC, Ullman TA, Talley NJ, Moayyedi P. Efficacy of immunosuppressive therapy for inflammatory bowel disease: a systematic review and metaanalysis. Am J Gastroenterol 2011;106:630-642.

192. Timmer A, McDonald JW, Tsoulis DJ, Macdonald JK. Azathioprine and 6-mercaptopurine for maintenance of remission in ulcerative colitis. Cochrane Database Syst Rev 2012;(9):CD000478. doi: 10.1002/14651858.CD000478.pub3.

193. Park SK, Yang SK, Ye BD, et al. The long-term efficacy of azathioprine in steroid-dependent ulcerative colitis. Scand J Gastroenterol 2013;48:1386-1393.

194. Dignass A, Eliakim R, Magro F, et al. Second European evidence-based consensus on the diagnosis and management of ulcerative colitis part 1: definitions and diagnosis. J Crohns Colitis 2012;6:965-990.

195. Actis GC, Bresso F, Astegiano M, et al. Safety and efficacy of azathioprine in the maintenance of ciclosporin-induced remission of ulcerative colitis. Aliment Pharmacol Ther 2001;15:1307-1311.

196. Campbell S, Ghosh S. Combination immunomodulatory therapy with cyclosporine and azathioprine in corticosteroidresistant severe ulcerative colitis: the Edinburgh experience of outcome. Dig Liver Dis 2003;35:546-551.

197. Ramakrishna J, Langhans N, Calenda K, Grand RJ, Verhave M. Combined use of cyclosporine and azathioprine or 6-mercaptopurine in pediatric inflammatory bowel disease. J Pediatr Gastroenterol Nutr 1996;22:296-302.

198. Domènech E, Garcia-Planella E, Bernal I, et al. Azathioprine without oral ciclosporin in the long-term maintenance of remission induced by intravenous ciclosporin in severe, steroid-refractory ulcerative colitis. Aliment Pharmacol Ther 2002;16:2061-2065. 
199. Siegel CA, Sands BE. Review article: practical management of inflammatory bowel disease patients taking immunomodulators. Aliment Pharmacol Ther 2005;22:1-16.

200. Present DH, Meltzer SJ, Krumholz MP, Wolke A, Korelitz BI. 6-Mercaptopurine in the management of inflammatory bowel disease: short- and long-term toxicity. Ann Intern Med 1989;111:641-649.

201. Connell WR, Kamm MA, Ritchie JK, Lennard-Jones JE. Bone marrow toxicity caused by azathioprine in inflammatory bowel disease: 27 years of experience. Gut 1993;34:1081-1085.

202. Fraser AG, Orchard TR, Jewell DP. The efficacy of azathioprine for the treatment of inflammatory bowel disease: a 30 year review. Gut 2002;50:485-489.

203. Kim JH, Cheon JH, Hong SS, et al. Influences of thiopurine methyltransferase genotype and activity on thiopurine-induced leukopenia in Korean patients with inflammatory bowel disease: a retrospective cohort study. J Clin Gastroenterol 2010;44:e242-e248. doi: 10.1097/MCG.0b013e3181d6baf5.

204. Ban H, Andoh A, Tanaka A, et al. Analysis of thiopurine Smethyltransferase genotypes in Japanese patients with inflammatory bowel disease. Intern Med 2008;47:1645-1648.

205. Takatsu N, Matsui T, Murakami Y, et al. Adverse reactions to azathioprine cannot be predicted by thiopurine S-methyltransferase genotype in Japanese patients with inflammatory bowel disease. J Gastroenterol Hepatol 2009;24:1258-1264.

206. Fangbin Z, Xiang G, Minhu C, et al. Should thiopurine methyltransferase genotypes and phenotypes be measured before thiopurine therapy in patients with inflammatory bowel disease? Ther Drug Monit 2012;34:695-701.

207. El-Matary W. Letter: thiopurine blood monitoring for patients with inflammatory bowel disease. Aliment Pharmacol Ther 2012;35:742

208. Yang SK, Hong M, Baek J, et al. A common missense variant in NUDT15 confers susceptibility to thiopurine-induced leukopenia. Nat Genet 2014;46:1017-1020.

209. Adedokun OJ, Xu Z, Marano CW, et al. Pharmacokinetics and exposure-response relationship of golimumab in patients with moderately-to-severely active ulcerative colitis: results from phase 2/3 PURSUIT induction and maintenance studies. J Crohns Colitis 2017;11:35-46.

210. Dulai PS, Siegel CA, Peyrin-Biroulet L. Anti-tumor necrosis factor-alpha monotherapy versus combination therapy with an immunomodulator in IBD. Gastroenterol Clin North Am 2014;43:441-456.

211. Gao X, Zhang FB, Ding L, et al. The potential influence of 5 -aminosalicylic acid on the induction of myelotoxicity during thiopurine therapy in inflammatory bowel disease patients. Eur J Gastroenterol Hepatol 2012;24:958-964.
212. de Boer NK, Wong DR, Jharap B, et al. Dose-dependent influence of 5-aminosalicylates on thiopurine metabolism. Am J Gastroenterol 2007;102:2747-2753.

213. Shah JA, Edwards CM, Probert CS. Should azathioprine and 5 -aminosalicylates be coprescribed in inflammatory bowel disease?: an audit of adverse events and outcome. Eur J Gastroenterol Hepatol 2008;20:169-173.

214. Beaugerie L, Brousse N, Bouvier AM, et al. Lymphoproliferative disorders in patients receiving thiopurines for inflammatory bowel disease: a prospective observational cohort study. Lancet 2009;374:1617-1625.

215. Lobel EZ, Korelitz BI, Xuereb MA, Panagopoulos G. A search for the optimal duration of treatment with 6-mercaptopurine for ulcerative colitis. Am J Gastroenterol 2004;99:462-465.

216. Chaparro M, Ordás I, Cabré E, et al. Safety of thiopurine therapy in inflammatory bowel disease: long-term follow-up study of 3931 patients. Inflamm Bowel Dis 2013;19:1404-1410.

217. Kozarek RA, Patterson DJ, Gelfand MD, Botoman VA, Ball TJ, Wilske KR. Methotrexate induces clinical and histologic remission in patients with refractory inflammatory bowel disease. Ann Intern Med 1989;110:353-356.

218. Ardizzone S, Petrillo M, Molteni P, Desideri S, Bianchi Porro G. Coated oral 5-aminosalicylic acid (Claversal) is equivalent to sulfasalazine for remission maintenance in ulcerative colitis: a double-blind study. J Clin Gastroenterol 1995;21:287-289.

219. Faubion WA Jr, Loftus EV Jr, Harmsen WS, Zinsmeister AR, Sandborn WJ. The natural history of corticosteroid therapy for inflammatory bowel disease: a population-based study. Gastroenterology 2001;121:255-260.

220. Bjarnason I, Macpherson A, Mackintosh C, Buxton-Thomas M, Forgacs I, Moniz C. Reduced bone density in patients with inflammatory bowel disease. Gut 1997;40:228-233.

221. Sandborn WJ, Feagan BG, Marano C, et al. Subcutaneous golimumab maintains clinical response in patients with moderate-tosevere ulcerative colitis. Gastroenterology 2014;146:96-109.e1.

222. Reinisch W, Sandborn WJ, Rutgeerts P, et al. Long-term infliximab maintenance therapy for ulcerative colitis: the ACT-1 and -2 extension studies. Inflamm Bowel Dis 2012;18:201-211.

223. Sandborn WJ, Rutgeerts P, Feagan BG, et al. Colectomy rate comparison after treatment of ulcerative colitis with placebo or infliximab. Gastroenterology 2009;137:1250-1260.

224. Sandborn WJ, Colombel JF, D'Haens G, et al. One-year maintenance outcomes among patients with moderately-to-severely active ulcerative colitis who responded to induction therapy with adalimumab: subgroup analyses from ULTRA 2 . Aliment Pharmacol Ther 2013;37:204-213. 
225. Reinisch W, Sandborn WJ, Panaccione R, et al. 52-week efficacy of adalimumab in patients with moderately to severely active ulcerative colitis who failed corticosteroids and/or immunosuppressants. Inflamm Bowel Dis 2013;19:1700-1709.

226. Williams CJ, Peyrin-Biroulet L, Ford AC. Systematic review with meta-analysis: malignancies with anti-tumour necrosis factor-alpha therapy in inflammatory bowel disease. Aliment Pharmacol Ther 2014;39:447-458.

227. Vande Casteele N, Gils A, Singh S, et al. Antibody response to infliximab and its impact on pharmacokinetics can be transient. Am J Gastroenterol 2013;108:962-971.

228. Paul S, Del Tedesco E, Marotte H, et al. Therapeutic drug monitoring of infliximab and mucosal healing in inflammatory bowel disease: a prospective study. Inflamm Bowel Dis 2013;19:2568-2576.

229. Parikh A, Fox I, Leach T, et al. Long-term clinical experience with vedolizumab in patients with inflammatory bowel disease. Inflamm Bowel Dis 2013;19:1691-1699.

230. Colombel JF, Sands BE, Rutgeerts P, et al. The safety of vedolizumab for ulcerative colitis and Crohn's disease [published online ahead of print February 18, 2016]. Gut. doi: 10.1136/ gutjnl-2015-311079.

231. Petkau JM, Eksteen B. Selective biologics for ulcerative colitis and Crohn's disease: clinical utility of vedolizumab. Biologics 2016;10:33-52

232. Rosario M, Wyant T, Milch C, et al. DOP058 Pharmacokinetic and pharmacodynamic relationship and immunogenicity of vedolizumab in adults with inflammatory bowel disease: additional results from the GEMINI 1 and 2 studies. J Crohns Colitis 2014;8:S42-S43.
233. Parks AG, Nicholls RJ. Proctocolectomy without ileostomy for ulcerative colitis. Br Med J 1978;2:85-88.

234. Lovegrove RE, Constantinides VA, Heriot AG, et al. A comparison of hand-sewn versus stapled ileal pouch anal anastomosis (IPAA) following proctocolectomy: a meta-analysis of 4183 patients. Ann Surg 2006;244:18-26.

235. Kariv R, Remzi FH, Lian L, et al. Preoperative colorectal neoplasia increases risk for pouch neoplasia in patients with restorative proctocolectomy. Gastroenterology 2010;139:806812.e2.

236. Williamson ME, Lewis WG, Sagar PM, Holdsworth PJ, Johnston D. One-stage restorative proctocolectomy without temporary ileostomy for ulcerative colitis: a note of caution. Dis Colon Rectum 1997;40:1019-1022.

237. Fleming FJ, Francone TD, Kim MJ, Gunzler D, Messing S, Monson JR. A laparoscopic approach does reduce short-term complications in patients undergoing ileal pouch-anal anastomosis. Dis Colon Rectum 2011;54:176-182.

238. Hull TL, Joyce MR, Geisler DP, Coffey JC. Adhesions after laparoscopic and open ileal pouch-anal anastomosis surgery for ulcerative colitis. Br J Surg 2012;99:270-275.

239. Trickett JP, Tilney HS, Gudgeon AM, Mellor SG, Edwards DP. Management of the rectal stump after emergency sub-total colectomy: which surgical option is associated with the lowest morbidity? Colorectal Dis 2005;7:519-522. 